\title{
Oil Volatility Risk and Expected Stock Returns
}

\author{
Peter Christoffersen and Xuhui (Nick) Pan
}

CREATES Research Paper 2015-6 


\title{
Oil Volatility Risk and Expected Stock Returns*
}

\author{
Peter Christoffersen \\ University of Toronto, \\ CBS and CREATES
}

\author{
Xuhui (Nick) Pan \\ Freeman School of Business, \\ Tulane University
}

December 2, 2014

\begin{abstract}
After the financialization of commodity futures markets in 2004-05 oil volatility has become a strong predictor of returns and volatility of the overall stock market. Furthermore, stocks' exposure to oil volatility risk now drives the cross-section of expected returns. The difference in average return between the quintile of stocks with low exposure and high exposure to oil volatility is significant at $0.66 \%$ per month, and oil volatility risk carries a significant risk premium of $-0.60 \%$ per month. In the postfinancialization period, oil volatility risk is strongly related with various measures of funding liquidity constraints suggesting an economic channel for the effect.
\end{abstract}

JEL Classifications: G12, G13, E44, Q02

Keywords: option-implied volatility; oil prices; volatility risk; cross-section; factormimicking portfolios; financial intermediaries.

${ }^{*}$ We would like to thank Ruslan Goyenko, Nishad Kapadia, David Lesmond, Neil Pearson, Wei Xiong as well as seminar participants at LSU, Tulane and the Rotman School for helpful comments. Christoffersen would like to thank SSHRC and Bank of Canada for financial support. Correspondence to: Peter Christoffersen, Rotman School of Management, University of Toronto, 105 St. George Street, Toronto, Ontario, Canada, M5P 3E6; Tel: (416) 946-5511; Fax: (416) 971-3048; E-mail: peter.christoffersen@rotman.utoronto.ca. 


\section{Introduction}

Since the energy crises of the 1970s large changes to the price of oil have received substantial attention in the popular and business press. Upward and downward moves appear to both get considerable mention as the recent sharp drop in the oil price has illustrated. Motivated by this observation we investigate the impact of oil price volatility, which captures positive surprises in price as well as negative, on the stock market. More broadly, our analysis is motivated by the desire to uncover links between the real economy and the cross section of equity markets. Such economic links have been difficult to detect as evidenced by the fact that the most popular equity market factors are constructed from firm characteristics (e.g. firm size and book-to-market values) and stock price moments (e.g. momentum and reversal) alone.

In the cross-section of equities we find that stocks with high (positive) exposure to oil volatility shocks earn significant lower average returns than stocks with low (negative) exposure. In the ICAPM model, only state variables that forecast future market returns and/or volatility are relevant. We therefore check and find that positive shocks to option-implied oil volatility indeed forecast negative future market returns and higher market volatility. We also find that increases in oil price uncertainty indicate tightening funding constraints of financial intermediaries, which in turn affect the stock market. This is consistent with Brunnermeier and Pedersen (2009) who argue that market uncertainty and financial intermediaries' capitals are interrelated state variables of the stock market.

Our analysis is structured to accommodate important recent changes in the commodity futures market. Regulatory changes and the availability of new commodity-linked securities have sharply increased the popularity of commodity futures investing and brought sweeping changes to futures price and volatility dynamics. Not surprisingly, this so-called "financialization" of commodity markets has also been the focus of a rapidly growing academic literature. ${ }^{1}$ Most authors including Baker (2012), Baker and Routledge (2012), Hamilton and $\mathrm{Wu}$ (2013), and Ready (2014) date financialization to take effect sometime in the 2004-2005 period. We follow these papers and consider two distinct sub-periods in our analysis: The pre-financialization period from 1990 through 2004, and the post-financialization period from 2005 through 2012. We rely on options on crude oil futures to compute volatility which restricts our overall sample to the post-1990 period.

\footnotetext{
${ }^{1}$ Early work on the topic includes Buyuksahin, Haig, Harris, Overdahl and Robe (2011), Singleton (2014), and Tang and Xiong (2012), and more recent contributions include Hamilton and Wu (2012), and Henderson, Pearson and Wang (2012). See also Basak and Pavlova (2013) for an important theoretical contribution and Cheng and Xiong (2013) for a survey of the literature.
} 
The top panel in Figure 1 shows the open interest and trading volume of the closestto-maturity crude oil futures contracts traded on the CME. The bottom panel shows open interest and trading volume of options written on the closest-to-maturity futures contracts. The sharp increase in open interest and trading volume for both futures and futures options is readily apparent. The vertical line represents January 3, 2005 which we will use as the default date to split the sample into pre- and post-financialization in the analysis below.

We find that the difference in average return between the quintile of stocks with the lowest (negative) exposure and the quintile of stocks with the highest (positive) exposure to oil volatility is $0.66 \%$ per month. The return spread is significant after controlling for the standard Carhart four factors and is robust to variations in the empirical design. Oil volatility carries a monthly risk premium of around $-0.60 \%$, which is both economically and statistically significant. These results are significant only in the post-financialization period. To investigate the economic sources that may drive this change, we find that from around 2005 oil volatility becomes a strong predictor of future returns and volatility in the overall stock market, which indicates its importance as an economic state variable. Shocks to oil volatility are also strongly related with various measures of funding constraints of financial intermediaries, which is arguably a key driver of pricing kernel dynamics (e.g. Adrian, Etula, and Muir, 2014). An increase in oil price volatility significantly tightens the funding constraint of intermediaries regardless of how the constraint is measured. This effect is much stronger in the post-financialization period than earlier. It suggests an economic channel for our results: increases in oil price volatility signal higher economic uncertainty and tightening funding constraints of financial intermediaries which are systematic factors of the stock market.

During 2005 - 2012, the hedge portfolio based on oil volatility risk delivers an average return of $0.50 \%$ per month with a Sharpe ratio of 0.16 , which are both higher than corresponding numbers for the market, size, book-to-market and momentum factors during the same period. The correlations between our oil volatility factor and other factors are low with a maximum magnitude of -0.19 with the market factor. Its correlation with $S M B, H M L$, and $U M D$ are $0.02,0.07$, and 0.02 , respectively. Oil volatility risk is thus not captured by the standard risk factors.

Our new oil volatility risk factor is defined as the innovation in option-implied oil price volatility, which we denote $\Delta I V O i l$. Stocks with a negative beta with $\Delta I V O i l$ earn a high average return (positive alpha) and stocks with positive beta with $\triangle I V O i l$ earn a low average return (negative alpha). Thus, stocks that perform poorly during positive shocks to $\Delta I V O i l$ earn a high return (and positive alpha) and stocks that perform well during positive shocks to $\triangle I V O i l$ earn a low return (and negative alpha). If positive shocks to $\triangle I V O i l$ signal 
deteriorating market and funding conditions, as our analysis suggests, then this is sensible: Stocks that perform poorly during deteriorating market and funding conditions need to earn a higher average return (and positive alpha) to be attractive to investors and vice versa. When sorting stocks on their beta with oil price returns, we find no significant spreads in stock returns. Our results therefore suggest that oil price risk is more relevantly captured by option-implied volatility than oil returns.

We do not find a significant spread in returns when sorting stocks on innovations in realized volatilities based on intraday oil futures returns. However, when we sort stocks on innovations in the oil volatility risk premium, defined as the difference between implied volatility and (expected) realized volatility, we find a similar pattern in expected returns as when sorting on $\triangle I V O i l$ exposure. Our results thus have interesting parallels with Bollerslev, Tauchen, and Zhou (2009), who use the variance risk premium from equity index options to capture uncertainty.

In addition to the recent work on the financialization of commodities, our paper is related to various strands of the literature. There is by now a mature but still growing literature investigating the impact on the economy from oil price shocks. This line of work broadly justifies why oil price risk may be a priced, systematic factor in the stock market. Barsky and Kilian (2004), Kilian (2008), and Hamilton (2008) succinctly survey the work in this area showing that oil price shocks have important effects on both inflation and real output. Hamilton (2008) has famously argued that "Nine out of ten of the U.S. recessions since World War II were preceded by a spike in the oil price." Our empirical findings confirm the distinct and important impact of oil on the stock market and thus on the economy as a whole.

There is a recent literature developing theoretical models for the pricing of oil risk. Carlson, Khokher and Titman (2007) develop an equilibrium model of exhaustible resource markets showing how stochastic volatility arises endogenously as a consequence of adjustment costs. Kogan, Livdan and Yaron (2009) develop an equilibrium model of oil production with irreversible investments and capacity constraints which also generates stochastic volatility in oil prices. In a general equilibrium production economy, Casassus, Collin-Dufresne and Routledge (2009) generate stochastic volatility when investment in new oil reserves is irreversible and costly. Acharya, Lochstoer and Ramadorai (2013) study the interaction of volatility with producers' hedging demand and futures risk premium in the oil and gas markets. Kellogg (2014) studies how uncertainty of the economic environment, measured by implied volatility from oil futures options, affects firms' investment decision. Other recent related work includes Baker and Routledge (2012) and Ready (2013). These papers highlight the significance of oil price volatility as opposed to the oil price itself.

There is a well-developed strand of literature investigating the relationship between com- 
modity prices including oil prices and stock prices (and other asset prices) at the broad market level. In their seminal study of economic forces in the stock market Chen, Roll and Ross (1986) find that oil price risk is not rewarded in the stock market. Jones and Kaul (1996) show that the reaction of stock markets to oil price shocks differ substantially across countries. Huang, Masulis and Stoll (1996) find no correlation between oil futures returns and stock returns except for oil companies. Ferson and Harvey (1993) use oil price shocks as a global economic risk variable to predict international equity markets. Kilian and Park (2009) document the importance of separating demand and supply shocks. Supply shocks have no effect on stock market returns but demand shocks do. We focus on oil volatility shocks. We do not find any effects from oil price shocks.

In recent work, Boons, de Roon and Szymanowska (2013) construct an index of commodity futures prices and find that stocks with high exposure to the commodity index earn a relative low average return in the pre-financialization period and a relatively high return in the post-financialization period. They develop a model that captures the structural break by restricting stock investors to participate in commodity futures trading in the prefinancialization period which causes stocks with commodity risk exposure (are considered as good hedges) to require a lower average return. As in Boons et al we find an important structural break at the onset of financialization. We differ from them by studying stock's exposure to commodity futures option implied volatility and by focusing on oil.

In another recent paper Chiang, Hughen, and Sagi (2013) develop an affine latent factor model with stochastic volatility which they fit to oil futures, oil futures options and oilrelated stocks. They then relate the extracted latent oil factors to macro variables and stock market risk factors. Interestingly, they find that the latent stochastic volatility factor appears to carry the most important relationship with the stock market factors. Our approach directly estimates individual stock's exposure to our model-free measure of oil option implied volatility and we emphasize the importance of the structural break caused by financialization. Moreover, by analyzing the different impacts of implied and realized volatility, our paper highlights the role of the oil volatility risk premium in explaining expected stock returns.

Finally, at the methodological level our work is related to the recent literature exploiting option price information when investigating the cross-section of stock returns. Ang, Hodrick, Xing and Zhang (2006) spearheaded this literature by showing that a stock's exposure to the option-implied stock market volatility, VIX, is an important determinant of its expected returns. Chang, Christoffersen and Jacobs (2013) find that a stock's exposure to optionimplied stock market skewness is priced as well. Bali and Zhou (2013) find that sorting on exposure to the variance risk premium also generates significant spreads in returns. Xing, Zhang and Zhao (2010) show that the shape of the volatility smirk in individual equity 
options has significant cross-sectional predictive power for future equity returns. Similarly, Conrad, Dittmar and Ghysels (2013) report on significant spreads in stock returns when sorting on firm-specific option-implied volatility, skewness and kurtosis.

The remainder of our paper is structured as follows. In Section 2 we present our optionbased measure of oil volatility risk and show that sorting equities on exposure to oil volatility risk generates a systematic pattern in expected stock returns. In Section 3 we show that innovations in oil volatility predict monthly return and volatility of the stock market. We also suggest an economic channel based on funding constraints of financial intermediaries. In Section 4 we compare the returns on our new oil volatility factor with returns on standard factors in the literature and provide estimates of the price of oil volatility risk in the crosssection of equity returns. Section 5 conducts various robustness exercises and further explores if our option-based oil volatility risk factor can be replaced by a simple oil return measure or return-based oil volatility proxies. Section 6 concludes.

\section{Oil Price Volatility Risk and Stock Returns}

In this section we first outline our procedure for computing option-implied volatility from crude oil futures options. We then perform simple univariate portfolio sorts on stocks' exposure to daily $\triangle I V O i l$. Finally, we conduct sequential sorts on market exposure and exposure to $\triangle I V O i l$.

\subsection{Measuring Oil Price Volatility Risk}

We begin our analysis by constructing a fixed-horizon, forward-looking measure of oil price volatility using crude oil futures options. We obtain the raw option data from the CME (formerly NYMEX) for the period 1990 through 2012. Liquidity of crude oil futures options was very low before 1990 and so following Trolle and Schwartz (2009) we begin our analysis in 1990. The crude oil option contracts are filtered using the following criteria: We exclude options with an open interest of fewer than 100 contracts or a price below $\$ 0.01$ and we exclude options violating standard no-arbitrage conditions. While crude oil options traded on the CME are American style, we convert the American option prices to European prices following Trolle and Schwartz (2009) who use the Barone-Adesi and Whaley (1987) approach. We finally eliminate contracts with a Black implied volatility smaller than $1 \%$ or larger than $200 \%$.

In order to estimate forward-looking volatility for each maturity using all the strike prices available, we rely on the model-free volatility extraction methodology developed and used by 
Bakshi and Madan (2000), Carr and Madan (2001), and Bakshi, Kapadia and Madan (2003). The central piece is the so-called quadratic contract, $M_{2}(t, T)$, which can be replicated by a portfolio of out-of-the-money (OTM) put and call options. If the underlying futures contract is delivered at $T^{\prime}, P\left(t, T, T^{\prime}, X\right)$ and $C\left(t, T, T^{\prime}, X\right)$ are the time $t$ price of a put option and a call option with strike price $X$ and maturity at $T$ with $T<T^{\prime}{ }^{2}$ When using $\log$ returns, the quadratic contract is replicated by options via the risk-neutral expectation

$$
\begin{gathered}
M_{2}(t, T)=E_{t}^{Q}\left[e^{-r(T-t)}\left(\frac{\log F_{T, T^{\prime}}}{\log F_{t, T^{\prime}}}\right)^{2}\right]= \\
\int_{0}^{F_{t, T^{\prime}}} \frac{2\left(1+\ln \left[F_{t, T^{\prime}} / X\right]\right)}{X^{2}} P\left(t, T, T^{\prime}, X\right) d X+\int_{F_{t, T^{\prime}}}^{\infty} \frac{2\left(1-\ln \left[X / F_{t, T^{\prime}}\right]\right)}{X^{2}} C\left(t, T, T^{\prime}, X\right) d X,
\end{gathered}
$$

where $F_{t, T^{\prime}}$ denotes the current price of the crude oil futures contract and $r$ denotes the annualized risk-free rate. When using simple returns, the quadratic contract can be replicated with puts and calls using

$M_{2}(t, T)=E_{t}^{Q}\left[e^{-r(T-t)}\left(\frac{F_{T, T^{\prime}}-F_{t, T^{\prime}}}{F_{t, T^{\prime}}}\right)^{2}\right]=\frac{2}{F_{t, T^{\prime}}^{2}}\left[\int_{0}^{F_{t, T^{\prime}}} P\left(t, T, T^{\prime}, X\right) d X+\int_{F_{t, T^{\prime}}}^{\infty} C\left(t, T, T^{\prime}, X\right) d X\right]$.

In either case the option-implied expected volatility from time $t$ to option maturity $T$, can be obtained via

$$
\operatorname{VOL}_{t}(T)=\left[e^{r(T-t)} M_{2}-M_{1}^{2}\right]^{1 / 2}
$$

where $M_{1}$ denotes the expected (log or simple) return to maturity $T$. Equation (2) shows most clearly that option-implied volatility is directly reflected in the out-of-the-money option price levels.

The key challenge in extracting option-implied volatility using these model-free measures is that a continuum of strike prices is not available in practice. Our implementation follows Duan and Wei (2010) who use a trapezoidal approximation to compute the integrals in (1).

We construct a 30-day fixed maturity implied volatility measure by interpolating the volatility estimates (3) from contracts with maturity just below and just above 30 calendar days. We refer to the resulting 30-day fixed maturity oil price volatility as IVOil below. Figure 2 plots the daily time series of $I V O i l$ in the top panel. The black line which begins in 1990 shows the IVOil measure. The grey line which begins only in 2007 shows CBOE's Crude Oil Volatility Index $(O V X) .{ }^{3}$ Note that in the $2007-2012$ period when both series

\footnotetext{
${ }^{2} \mathrm{CME}$ crude oil futures contracts expire on the third business day prior to the 25th of the month before the delivery month, if the 25 th is a business day. If the 25 th is not a business day then the preceding day is used. Options written on futures expire three business days before the expiration of the futures contract.

${ }^{3} \mathrm{CBOE}$ uses the VIX methodology to compute OVX based on options traded on the United States Oil
} 
are available, our computed IVOil tracks $O V X$ very closely with a correlation higher than 98.5\%. Note also the very high degree of persistence in IVOil. The vertical line in Figure 2 denotes January 3, 2005. For reference, the middle panel in Figure 2 shows the daily nearest-to-maturity futures price for the $1990-2012$ period. The plot is dominated by the dramatic run-up in oil prices in 2007, the crash in 2008 and the subsequent recovery. The bottom panel in Figure 2 plots the familiar daily closing values on the S\&P500 index.

We are interested in investigating the returns on individual equities with varying degrees of exposure to oil price volatility risk. We therefore need to construct a measure of unexpected variation in our IVOil series. Fortunately, Figure 3 shows that this is quite easily done. The top panel of Figure 3 shows the autocorrelation function for IVOil for lags of 1 through 20 trading days. The horizontal dashed lines around zero denote the Bartlett $95 \%$ confidence band constructed under the null that each autocorrelation is zero. The level of $I V O i l$ is clearly extremely persistent. The bottom panel of Figure 3 shows the autocorrelations of the first differences in daily IVOil, which we denote $\Delta I V O i l$ below. Note that all 20 autocorrelations fall within or close to the Bartlett $95 \%$ confidence bands, and that taking simple first differences thus removes the systematic pattern in the autocorrelations of the original IVOil time series. Using first differences also enables us to directly compare our analysis with other papers studying stock exposures on the CBOE stock market volatility index (VIX) such as Ang, Hodrick, Xing, and Zhang (2006) among others. We therefore rely on $\triangle I V O i l$ as our measure of oil volatility risk below.

The top-left panel of Figure 4 plots the daily innovation of IVOil that we use throughout the paper, along with the daily innovation of VIX in the bottom-left panel. Note that the two series share some commonalities in 2008 but display large differences in the remainder of the sample. In the top-right panel we plot the daily oil returns calculated from futures prices and the bottom-right panel shows the daily returns on a value-weighted index of all U.S. firms in CRSP, which is downloaded from Ken French's data library. Note that oil returns are much more variable than stock market returns in our sample.

Table 1 reports further on the correlations between our new daily $\Delta I V O i l$, the excess stock market return $R_{m}-R_{f}$, daily oil return calculated from futures prices, and first differences in $\operatorname{VIX}(\Delta V I X)$, as well as correlations with size (SMB) and value (HML) from Fama and French (1993), momentum (UMD) from Carhart (1997). It shows that oil returns are only weakly correlated with other variables in the 1990-2004 sample and that the correlation with the market return is moderate at 0.35 in the 2005-2012 sample. Meanwhile, the so-called leverage effect (the negative correlation between market returns and $\Delta V I X$ ) is Fund, LP. USO is an ETF that maintains a large position in the near-term crude oil futures contact. We construct IVOil directly from options on oil futures because USO options are not available prior to 2007 . 
strong in both the 1990-2004 sample at -0.72 and in the $2005-2012$ sample at -0.84 . The third row of correlations show that $\triangle V I X$ and $\Delta I V O i l$ are only weakly correlated at 0.14 in the first subsample and moderately correlated at 0.37 in the second subsample. Interestingly our daily $\triangle I V O i l$ has very low contemporaneous correlations with SMB, HML, and UMD in either sample period, while the correlation between $\Delta V I X$ and these risk factors are not trivial. Figure 5 contains scatter plots of $\Delta I V O i l, \Delta V I X$, the excess market return, and oil return from 2005 to 2012. It confirms the salient negative relationship between excess stock market returns and $\Delta V I X$. We also observe that oil returns are positively correlated with the excess stock market return after 2005. In summary, we find that our new $\Delta I V O i l$ risk factor is only moderately correlated with other standard risk factors.

\subsection{Univariate Portfolio Sorts}

We now proceed to one of our main tasks. We use daily $\Delta I V O i l$ described in Section 2.1 to test if oil price volatility is priced in the cross-section of stock returns. In order to get an assessment of the cross-sectional pricing of oil volatility exposure we carry out simple univariate portfolio sorts in this section. At the end of each month, we run the following regression for each firm on daily returns during the month

$$
R_{i, t}-R_{f, t}=\beta_{0}^{i}+\beta_{M K T}^{i}\left(R_{m, t}-R_{f, t}\right)+\beta_{I V O i l}^{i} \Delta I V O i l_{t}+\varepsilon_{i, t},
$$

where $R_{i, t}$ is the daily return on stock $i$ and $R_{f, t}$ is the risk-free rate. Here, and in the analysis below, we use returns on all stocks included in the NYSE/Amex/Nasdaq file obtained from CRSP. After running the time series regressions in (4) on each stock, we sort stocks into five quintiles based on $\beta_{I V O i l}^{i}$ with the first quintile having the lowest beta and the fifth having the highest beta. We form five value-weighted portfolios at the end of each month and record the daily returns of each quintile portfolio for the following month. We repeat the procedure by rolling the beta estimation window forward one month at a time. Our setting is similar to Pastor and Stambaugh (2003) and Ang, Hodrick, Xing and Zhang (2006), among others, who use daily returns within a one-month window to capture dynamics in the factor exposures.

Using daily returns on the five post-ranking portfolios $R_{p}-R_{f}$, we run the following Carhart (1997) four-factor regression

$$
R_{p, t}-R_{f, t}=\alpha^{p}+\beta_{M K T}^{p}\left(R_{m, t}-R_{f, t}\right)+\beta_{S M B}^{p} S M B_{t}+\beta_{H M L}^{p} H M L_{t}+\beta_{U M D}^{p} U M D_{t}+\varepsilon_{p, t} .
$$

We then test whether a hedge-portfolio strategy that buys the $20 \%$ of stocks with the largest $\beta_{\text {IVOil }}$ and sells the $20 \%$ of stocks with the smallest $\beta_{I V O i l}$ earns abnormal returns. The parameter of interest is the estimated intercept, Jensen's alpha, denoted by $\alpha^{p}$. If $\alpha^{p}$ is 
significantly different from zero, the Carhart four factor model cannot explain excess returns, and oil price volatility is said to be priced in the stock market. We examine this hypothesis on each of our two sub-samples: January 1990 to December 2004 (pre-financialization), and January 2005 to December 2012 (post-financialization).

In Table 2 we report the average pre-ranking and post-ranking beta and post-ranking returns per month (\%) for each quintile portfolio. We also report monthly post-ranking Jensen's alpha (\%) which is daily alpha multiplied by 21 . In parentheses are Newey and West (1997) t-statistics with 12 lags for monthly returns and 21 lags for daily alpha regressions. For parsimony, we do not tabulate t-statistics of returns and alphas for every portfolio. For the pre-financialization period $(1990$ - 2004) average returns and alphas of the hedge-portfolio strategy are close to zero and not significant. However, during the post-financialization period $(2005-2012)$ buying the highest $\beta_{I V O i l}^{i}$ quintile stocks and selling the lowest quintile $\beta_{I V O i l}^{i}$ stocks earns an average of $-0.66 \%$ per month or $-7.92 \%$ per year. The average return has a t-stat of -2.49 and is thus significant at conventional levels. The corresponding Carhart alpha is $-0.75 \%$ per month or $-9 \%$ per year, which is also significant at the $10 \%$ level with a t-stat of -1.92 . Throughout the tables we boldface t-stats larger than 1.68 (rather than 1.96) in magnitude because our subsamples are relatively short. Notice that the post-ranking betas monotonically increase across quintiles, and that the magnitudes of our post-ranking betas are comparable with those in Ang, Hodrick, Xing and Zhang (2006) who form monthly portfolios based on daily regressions on the VIX. Our average returns and Carhart alphas are monotonically decreasing across quintiles. The results suggest that oil volatility risk is negatively associated with future expected stock returns. The average book-to-market ratio and the average firm size in each quintile portfolio show that our results are not driven by value or size effects.

The upper panel of Figure 6 plots average monthly returns and Jensen's alpha of the hedge portfolio. We use a 5-year rolling window to investigate how the returns on the hedge portfolio evolve across time. The circle (asterisk) for year 1994, for example, is based on return (alpha) data from 1990 - 1994 and the circle (asterisk) for year 1995 is based on 1991 - 1995 returns (alpha). We note that average monthly returns on this portfolio are small in magnitude before 2005, fluctuating around zero. From 2005 returns are consistently larger in magnitude and have been relatively stable. The lower panel of Figure 6 reports t-statistics of alphas from the Carhart 4-factor model. Following Fama and French (1988) we rely on Hansen and Hodrick's (1980) t-stats which correct standard errors for overlapping data. The lower panel of Figure 6 shows that in the 5-year samples ending prior to 2005 alphas and returns are never significant, whereas in the 5-year samples post-2005 alphas are mostly beyond or close to the edge of the confidence band which we have drawn from 
-1.68 to +1.68 acknowledging the relatively short samples at hand. The results are similar if we use 4 or 6 -year windows. Figure 6 thus confirms that oil volatility risk begins to have significant impact on stock returns around 2005.

\subsection{Sequential Portfolio Sorts}

Using the bivariate regressions in (4) we can form 25 portfolios using the following procedure. At the end of each month, we first sort stocks into 5 quintiles based on $\beta_{M K T}$ with the first quintile having the lowest $\beta_{M K T}$ and the fifth having the highest $\beta_{M K T}$. Within each quintile, we then sort stocks based on $\beta_{\text {IVOil }}$ which now yields 25 sequentially sorted portfolios. We then record daily post-ranking returns for each portfolio in the following month.

We next split the 25 portfolios into groups with exposure to only one factor, i.e. either $R_{m}-R_{f}$ or $\triangle I V O i l$. This grouping is performed in order to accentuate the cross-sectional exposure to one factor, while keeping the exposure to the other factor constant. Within each group, we compute the value-weighted returns for each portfolio in the following month. Using the above procedure, we calculate monthly returns and Jensen's (Carhart four-factor) alpha of the hedge portfolio from buying the highest beta exposure and selling the lowest beta exposure.

Table 3 reports average post-sorting monthly returns and average post-sorting alphas for each risk factor. The Newey-West t-stats for the difference in average returns and average alphas between the highest and the lowest exposures are in parentheses. We report sorting results based on $\beta_{M K T}$ and $\beta_{I V O i l}$ in Panel A and B respectively. Again we focus on two sub-periods: 1990 - 2004 and 2005 - 2012. Panel B of Table 3 confirms the results of Table 2: When keeping market exposure constant in the 2005 - 2012 period the return spread of portfolios sorted on oil volatility risk is $-0.50 \%$ per month with a t-stat of -2.68 . The corresponding Carhart alpha is $-0.50 \%$ per month with a t-stat of -1.47 . While the Carhart alpha is of the same magnitude as the average return, it is not as precisely measured.

The spread in returns is not significant in the 1990 - 2004 period (top of Panel B); nor is it significant for the $\beta_{M K T}$ sensitive portfolios (Panel A) where we have kept the exposure to oil volatility risk constant. Table 3 also shows that the oil volatility risk effect on the cross-section of expected returns is clearly different from the market-return effect.

In summary, we have found strong evidence that stocks with relatively large exposure to oil price volatility risk earn a relatively low future return on average. This is presumably because they serve as a valuable hedge for an important systematic risk in the economy. We now investigate the nature of this risk. 


\section{The Economics of Oil Price Volatility Risk}

In this section we first analyze if $\triangle I V O i l$ can help forecast market return and volatility and thus justify that oil volatility is a state variable in the stock market. We then explore funding liquidity constraints as a potential economic channel for oil price volatility risk to impact the stock market.

\subsection{Forecasting Stock Market Return and Volatility}

Cochrane (2005) argues that "...the only state variables in the ICAPM are those that forecast future market returns." Bloom (2009) highlights the importance of capturing macrouncertainty shocks. Bloom's use of market volatility as a proxy for macro uncertainty is justified by Schwert (1989) who shows that changes in market volatility are partly driven by changes in the volatility of macroeconomic variables. Bansal, Kiku, Shaliastovich, and Yaron (2014) argue that macroeconomic volatility risk is an important determinant of asset prices. Robe and Wallen (2014) find strong interactions between option implied oil volatility and global macroeconomic conditions. Bakshi and Chen (1996) argue specifically that uncertainty in commodity prices is a state variable because it affects the set of available consumption goods and investment opportunities and therefore investors' portfolio choices and stock prices. In order to substantiate the conjecture that oil volatility is a state variable in economy, we now investigate if oil volatility innovations help predict-in a time series sense-future returns and volatility in the overall stock market.

We first regress monthly excess value-weighted CRSP returns, $R_{m}-R_{f}$, on lagged monthly $\triangle I V O i l$ as well as on lagged monthly $\Delta V I X$, lagged monthly market excess returns and a constant. We always include lagged market returns but consider different combinations of the lagged monthly $\triangle I V O i l$ and $\triangle V I X$ variables. Second we regress monthly stock market volatility, which is computed as the standard deviation of daily excess market returns during the month, on lagged monthly $\Delta I V O i l$, lagged monthly $\Delta V I X$, lagged monthly market volatility and a constant. We conjecture that market returns and market volatility are partly predictable using $\triangle I V O i l$ after the financialization of commodity markets.

Panel A of Table 4 reports the results of the monthly return forecasting exercise. We do not find any evidence of predictability of market returns during $1990-2004$. All coefficients are insignificant and the adjusted $R^{2}$ is negative in all regressions. For the $2005-2012$ period, the lagged market excess return alone has a positive slope and generates an adjusted $R^{2}$ of $3.53 \%$ per month. We also note that $\triangle I V O i l$ is a significant predictor of next month's market return. When adding lagged $\Delta I V O i l$ to the regression its coefficient is highly significant and the adjusted $R^{2}$ jumps from $3.53 \%$ to $8.23 \%$. 
The magnitude of this $R^{2}$ is strikingly large and economically significant. Ross (2005) derives an upper bound for $R^{2}$ in predictive regressions to be $R^{2} \leq\left(1+R_{f}\right)^{2} \operatorname{var}(\xi) \leq$ $\gamma^{2} \operatorname{var}\left(R_{m}\right)$, where $\xi$ is the pricing kernel and $\gamma$ denotes the coefficient of risk aversion for the representative investor. If we choose $\gamma$ to be a reasonable value of 5 , and if we calibrate stock market volatility using the volatile period from January 2007 to December 2009 in our data sample, the upper bound for $R^{2}$ in the monthly predictive regressions is $9.36 \%$. With a value of $8.23 \%, R^{2}$ in the predictive regression using lagged market return and lagged $\Delta I V O i l$ is close to the upper bound. It suggests that oil price volatility has become a strong market return predictor and an important state variable since $2004-2005$.

Conversely, we do not find evidence of predictability when using stock market volatility, $V I X$, as a predictor. Although both volatility measures have negative slope estimates, monthly $\Delta V I X$ is never significant. When adding lagged monthly $\Delta V I X$ to the regression containing lagged market return, the slope of $\Delta V I X$ is insignificant and the adjusted $R^{2}$ drops from $3.53 \%$ to $2.91 \%$. When adding lagged monthly $\Delta V I X$ to the regression containing lagged market return and lagged $\Delta I V O i l$, the slope coefficient on lagged $\Delta V I X$ is again not significant and the adjusted $R^{2}$ drops slightly from $8.23 \%$ to $7.35 \%$. The slope of $\Delta I V O i l$ remains significant with a t-stat of -2.39 .

Panel B of Table 4 reports the results from forecasting monthly stock market volatility. Monthly market volatility-unlike monthly market return-is highly persistent and so lagged monthly volatility alone provides an adjusted $R^{2}$ of $46.08 \%(61.09 \%)$ in the $1990-2004$ $(2005-2012)$ period. In $2005-2012$, when we include lagged monthly $\Delta I V O i l$ or $\Delta V I X$, both are significant and add a few percentage points to the adjusted $R^{2}$. It is natural that $\triangle V I X$ can predict future market volatility as $V I X$ is an option-based measure of expected market volatility. However, when we include monthly $\triangle I V O i l$ in the predictive regression with lagged market volatility and lagged $\Delta V I X$, the adjusted $R^{2}$ still increases by $1.33 \%$, suggesting that $\triangle I V O i l$ provides new information not fully captured by $\Delta V I X$. Interestingly, in the $1990-2004$ period, lagged $\Delta V I X$ is significant but lagged $\Delta I V O i l$ is not, suggesting again the important changes occurring during financialization in $2004-2005$.

We conclude from Table 4 that option-implied oil volatility appears to be an important state variable of the economy. In an ICAPM setting, investors will prefer stocks that do well when the market deteriorates (i.e. when $\triangle I V O i l$ is positive) and will hold them even if their expected returns are relatively low. This is exactly the result we found in Tables 2 and 3 above. We next investigate a potential economic channel for oil price volatility to impact the stock market. 


\subsection{Funding Constraints of Financial Intermediaries}

Brunnermeier and Pedersen (2009) have argued that market volatility and financial intermediaries' capitalization levels are interrelated state variables of the stock market. Financial intermediaries are active in many markets simultaneously, and they need to finance trading using their own capital and/or collateralized borrowing from other financiers. When market volatility is high, margins increase and intermediaries become more capital constrained. Likewise, in market downturns, financial intermediaries are more likely to be capital constrained. Therefore when market volatility is high, financial intermediaries will be more constrained either due to higher margins, declines of their portfolio value, or both. Given the fact that higher IVOil is associated with more uncertainty and negative returns in the market after financialization (see Section 3.1), positive shocks to IVOil will be transmitted to the stock market through the decrease in risk-bearing capacity of intermediaries. Positive shocks to volatility (positive $\triangle I V O i l$ ) lead to higher margins or lower values of intermediaries' assets, which tightens speculators' funding constraints, lowers market liquidity, and further increases the magnitude of risk premia. This mechanism is consistent with Adrian, Etula, and Muir (2014) who argue that the marginal value of wealth of financial intermediaries is a key driver of pricing kernel dynamics.

To investigate if shocks to IVOil are directly related to shocks to funding constraints faced by financial intermediaries, we regress contemporaneous shocks to funding constraint variables on shocks to IVOil,

$$
\Delta \text { Funding }_{t}=b_{0}+b_{1} * \Delta I V O i l_{t}+e_{t} .
$$

We compare the pre- and post- financialization periods. Following the literature, we identify eight measures of funding constraints which are available during our sample period, 1990 - 2012. They include broker-dealer leverage (Adrian, Etula, and Muir, 2014), the betting against beta (BAB) factor (Frazzini and Pedersen, 2014), the funding liquidity factor (Fontaine and Garcia, 2011), the prime broker index (PBI), the Datastream bank index (BANK), credit spreads, and the TED spread used by Boyson, Stahel, and Stulz (2010). We also consider the Pastor and Stambaugh (2003) liquidity factor.

We compute shocks to broker-dealer leverage from the quarterly Flow of Funds report from the Federal Reserve. Financial intermediaries become more constrained when their leverage decreases. Negative shocks to leverage are therefore associated with decreases in risk-taking and decreases in asset growth. The BAB factor measures returns of a portfolio that is long low-beta stocks and short high-beta stocks. When the return on the BAB factor is low, funding constraints tighten. Funding liquidity captures the shadow cost of capital for financial intermediaries. It increases when the supply of funds is limited. Positive shocks to 
funding liquidity imply worse funding conditions and higher financing costs. Therefore, we expect that shocks to IVOil are negatively related to shocks to the broker-dealer leverage and the BAB factor, but are positively related with the funding liquidity factor.

The variable PBI is an equally weighted stock price index of prime broker firms. ${ }^{4}$ BANK is an equally weighted stock price index of large commercial banks obtained from Datastream. Shocks that decrease the financial strength of intermediaries, which are reflected in decreases in PBI and BANK, imply that broker-dealers are more constrained and/or face higher margin requirements. Shocks to uncertainty increase margins and tighten financial constraints. Thus we expect that $\triangle I V O i l$ is negatively related to PBI and BANK. Credit spreads are measured using Baa and 10-year maturity Treasury bonds; the TED spread is the spread between 3month LIBOR and 3-month Treasury bonds. Increased spreads imply higher borrowing costs and/or counterparty risk, which we expect to be positively related with $\Delta I V O i l$. Finally, increasing levels of uncertainty (positive $\Delta I V O i l$ ) should decrease market liquidity as suggested by Brunnermeier and Pedersen (2009). This is because uncertainty increases margins and reduce broker-dealers' capability to provide liquidity.

Except for broker-dealer leverage data which is only available quarterly, shocks to all other variables are measured monthly in Table 5 to match our one-month stock-sorting exercise. We report the regression coefficients $b_{1}$ from equation (6) in Panel A of Table 5. The results show that after the financialization of commodity markets, shocks to IVOil are clearly associated with tightening funding constraints of financial intermediaries. Most coefficients are significant at the $5 \%$ level or better after financialization. Interestingly, shocks to IVOil are not related with shocks to broker-dealer leverage and funding liquidity before 2005, but their relationship is highly significant afterwards.

We next ask if shocks to our forward-looking IVOil measure lead shocks to funding constraints faced by financial intermediaries. To this end we perform predictive regressions and investigate whether shocks of IVOil in period $t$ can predict shocks of funding constraints of financial intermediaries in period $t+1$

$$
\Delta \text { Funding }_{t+1}=b_{0}^{\prime}+b_{1}^{\prime} * \Delta I V O i l_{t}+e_{t+1}^{\prime}
$$

We use the same set of variables measuring funding conditions of financial intermediaries as in our contemporaneous regressions in equation (6). As reported in Panel B of Table 5, we find that shocks to oil volatility can significantly predict four out of eight measures of funding constraints after financialization. For instance, $\Delta I V O i l$ in the current month can

\footnotetext{
${ }^{4}$ The prime brokers are: Goldman Sachs, Morgan Stanley, Bear Stearns, UBS AG, Bank of America, Citigroup, Merrill Lynch, Lehman Brothers, Credit Suisse, Deutsche Bank, and Bank of New York Mellon. Stock price data are obtained from CRSP.
} 
predict shocks to credit spreads in the next month with an adjusted $R^{2}$ of $9.7 \%$. Although some other variables such as broker-dealer leverage and funding liquidity are not significant, their coefficients have the expected sign.

In summary, we show that shocks to oil volatility are strongly associated with various measures of funding constraints faced by financial intermediaries after financialization, and that $\triangle I V O i l$ can predict several funding constraint variables. It suggests that due to increased activity in the commodity market by financial intermediaries post financialization, $\triangle I V O i l$ captures their funding constraints quite well. Our results suggest the importance of oil price uncertainty in the stock market through a financial intermediary channel, and we thus complement the recent literature (e.g. Chiang, Hughen, and Sagi, 2013) which relates oil volatility with traditional macroeconomic variables such as GDP and industrial production growth.

\section{Factor Portfolios and the Price of Oil Volatility Risk}

In this section we analyze further the returns on the $\Delta I V O i l$-sensitive spread portfolio from Panel B of Table 3. We then compute the price of oil volatility risk using various factor models.

\subsection{Factor Portfolios}

We will refer to the $\triangle I V O i l$-based factor portfolio as FIVOil below, and returns on this portfolio can be used as a proxy for the risk factor. To be explicit, consider a $5 \times 5$ portfolio return matrix $P$, where row 1 contains the stocks with the lowest market betas, row 5 contains the row with the highest market betas, column 1 contains the stocks with the lowest $\Delta I V O i l$ betas and column 5 contains the stocks with the highest $\Delta I V O i l$ betas. From this matrix of portfolios we can construct the FIVOil portfolio return using

$$
\text { FIVOil }=(1 / 5)\left(P_{1,5}+P_{2,5}+P_{3,5}+P_{4,5}+P_{5,5}\right)-(1 / 5)\left(P_{1,1}+P_{2,1}+P_{3,1}+P_{4,1}+P_{5,1}\right) .
$$

We next compare returns on the oil volatility mimicking portfolio FIVOil with returns on standard factor portfolios in the literature, namely $R_{m}-R_{f}, S M B, H M L$ and $U M D$. We also compare FIVOil returns with returns on a market volatility mimicking portfolio, that is, a VIX-based factor portfolio which we construct as follows: At the end of each month, we run the following regression using daily stock returns

$$
R_{i, t}-R_{f, t}=\beta_{0}^{i}+\beta_{M K T}^{i}\left(R_{m, t}-R_{f, t}\right)+\beta_{V I X}^{i} \Delta V I X_{t}+\varepsilon_{i, t},
$$


where $\Delta V I X_{t}$, as above, is the daily first-difference in the $V I X$ index. We then repeat the sequential portfolio sort in Table 3 , but now using $\beta_{V I X}^{i}$ as the sorting variable in the second step. From this exercise we obtain the $V I X$-based (factor) portfolio FVIX using the approach in (8), and we record the daily returns of this portfolio.

Table 6 reports the average monthly return of each factor portfolio and the corresponding Newey-West t-stat for the $1990-2004$ and 2005 - 2012 periods. We also report the matrix of sample correlations for the six factors we consider. In the $1990-2004$ period FVIX, the market and the momentum portfolios are all significant. The FIVOil factor has a rather low average return and is not significant in the pre-financialization period. However, in the 2005 - 2012 period, FIVOil is the only portfolio with a significant return. The return is $-0.50 \%$ per month which is larger in magnitude than all the other portfolios. The Sharpe ratio of 0.16 for FIVOil is impressive given the high level of volatility during the period.

Interestingly, FIVOil has a low contemporaneous correlation with the other risk factors which have traditionally been viewed to be important. The correlation between FIVOil and each of the other five factors has a maximum magnitude of -0.19 for the market factor, and its correlation with $S M B, H M L$, and $U M D$ is $0.02,0.07$, and 0.02 respectively. The correlation between $F V I X$ and the market factor on the other hand is -0.58 , the correlation with $U M D$ is 0.54 , and the correlations with $S M B$ and $H M L$ are also relatively large at -0.33 and -0.35 . The FIVOil factor thus appears to be much less related to standard factor portfolios than is FVIX.

The top-left panel of Figure 7 plots the (negative of the) cumulative return on the FIVOil factor. The other three panels report cumulative returns on the standard size (top-right), value (bottom-left), and momentum (bottom-right) factors during the 2005 - 2012 period. Note that the cumulative FIVOil returns have been increasing steadily whereas the other three factors have gone through long periods of cumulative return declines. The most dramatic decline occurred in the momentum portfolio in early 2009 when the overall market recovered, and the short position in financials resulted in large losses in the momentum portfolio as financials recovered strongly. Note that overall during the post-financialization period the oil volatility risk factor outperforms the size factor, the value factor, and the momentum factor.

Figure 8 plots the (negative of the) cumulative returns on the FIVOil factor along with the (negative of the) cumulative returns on the FVIX factor. Figure 8 shows that while the overall performances of FIVOil and FVIX are somewhat similar during 2005 - 2007 and 2009 - 2010 they are very different during 2007 - 2009 and $2010-2012$. Furthermore, the month-to-month variation in the two series is quite different as also suggested by the low correlation estimate in Table 6. In summary, the FIVOil factor performs quite differently 
from other standard factors. This suggests that oil price volatility may carry a risk premium that is not captured by other factors.

\subsection{The Price of Oil Volatility Risk}

We now test if oil volatility carries a significant risk premium. In order to estimate the price of oil volatility risk we apply the two-pass regressions of Fama and MacBeth (1973) to the 25 market and IVOil sorted portfolios defined above. In the first stage, we estimate betas by running a time series regression on the full sample of monthly returns on the 25 portfolios. In the second stage, we regress the cross section of excess returns of the 25 portfolios on their estimated factor betas to obtain the estimate of the price of risk, $\lambda$, each month. For comparison, we also perform two-pass regressions using 25 market and VIX sorted portfolios constructed using the same procedure. We consider two different factor model specifications:

- CAPM plus FIVOil (or FVIX)

- Carhart 4-factor plus FIVOil (or FVIX)

The cross-sectional expected return in the model with the four Carhart factors plus FIVOil can be written as

$E\left[R_{i}\right]-R_{f}=\lambda_{0}+\lambda_{M K T} \beta_{M K T}^{i}+\lambda_{F I V O i l} \beta_{F I V O i l}^{i}+\lambda_{S M B} \beta_{S M B}^{i}+\lambda_{H M L} \beta_{H M L}^{i}+\lambda_{U M D} \beta_{U M D}^{i}$.

The cross-sectional expected return in the Carhart 4-factor plus FVIX model can be written as

$$
E\left[R_{i}\right]-R_{f}=\lambda_{0}+\lambda_{M K T} \beta_{M K T}^{i}+\lambda_{F V I X} \beta_{F V I X}^{i}+\lambda_{S M B} \beta_{S M B}^{i}+\lambda_{H M L} \beta_{H M L}^{i}+\lambda_{U M D} \beta_{U M D}^{i} .
$$

If the risk premium associated with oil volatility $\lambda_{F I V O i l}$ (or market volatility $\lambda_{F V I X}$ ) is significant, i.e. if FIVOil (or FVIX) carries a significant risk premium, then we say that the oil volatility (market volatility) risk factor is priced.

Table 7 reports the average regression coefficients (our $\lambda$ estimates) as well as the adjusted $R^{2}$ from the cross-sectional regressions. In the $1990-2004$ period we note that $\lambda_{F I V O i l}$ is negative but insignificant. On the other hand, $\lambda_{F V I X}$ is $-0.56 \%$ per month when using the specification in equation (11) and statistically significant at the $5 \%$ level. For the 2005-2012 period, we see that the FIVOil factor is significantly priced in both specifications. In the CAPM plus FIVOil specification the price of oil volatility risk is $-0.58 \%$ per month with a t-stat of -2.69. In the Carhart 4-factor plus FIVOil specification in equation (10) the price 
of FIVOIL risk is $-0.60 \%$ with a t-stat of -2.80 . Judging by the magnitude of the price of risk, oil volatility risk seems to be at least as important as stock market volatility risk.

We next test if oil volatility risk is priced in the cross section using another estimation method. In the first step of the Fama and MacBeth (1973) regressions, we now rely on rolling one-month sample estimates of betas using daily returns rather than the full sample estimation on monthly returns used in Table 7 . We estimate the $\lambda \mathrm{s}$ by running cross-sectional regressions on monthly returns. We report average regression coefficients and adjusted $R^{2}$ in the cross-sectional regressions, as well as the Newey-West t-statistics computed with 12 lags. The parameters of interest are $\lambda_{\text {FIVOil }}$ and $\lambda_{\text {FVIX }}$.

We report the results in Table 8 . It shows that $\lambda_{F V I X}$ becomes smaller in magnitude during $1990-2004$ when we adopt the new estimation approach. To be specific, $\lambda_{F V I X}$ changes from $-0.56 \%$ in per month in Table 7 to $-0.34 \%$ in Table 8 and it loses statistical significance. However, the price of oil volatility risk is robustly significant in $2005-2012$. In the CAPM plus FIVOil specification, the price of oil volatility risk is $-0.61 \%$ (in Table 8) versus $-0.58 \%$ (in Table 7). In the Carhart 4-factor plus FIVOil specification, the price of oil volatility risk is $-0.56 \%$ in Table 8 versus $-0.60 \%$ in Table 7 . Both $\lambda_{\text {FIVOil }}$ estimates are statistically and economically significant. Table 8 shows that our results in Table 7 are robust to the choice of estimation technique. These findings confirm that oil volatility risk is priced in the stock market and that the price of oil volatility risk is negative.

We next perform the Fama-MacBeth two-pass analysis on 49 Fama-French industry portfolios. All the portfolio data are from Ken French's data library. To fully reflect timevariation in betas, we use a rolling one-month sample to estimate them. We then estimate $\lambda \mathrm{s}$ by running cross-sectional regressions on monthly returns. We report average regression coefficients and adjusted $R^{2}$ in the cross-sectional regressions, as well as the Newey-West tstatistics with 12 lags. We report on CAPM and Carhart 4-factor specifications plus FIVOil (and FVIX). Table 9 summarizes results for our two sub-sample periods: $1990-2004$ and 2005 - 2012. During the $1990-2004$ period, only $S M B$ is significant for the 49 industry portfolios, and the price of size risk $\lambda_{S M B}$ is around $-0.37 \%$ per month. The negative premium on $S M B$ is consistent with findings in other papers such as Ang, Hodrick, Xing and Zhang (2006). The other factors are not significant. For the $2005-2012$ period, we note that FIVOil is significantly priced in both models considered. The price of FIVOil risk ranges from $-0.43 \%$ to $-0.56 \%$ per month. Other standard factors are not significant. Overall, using different estimation approaches and different testing portfolios, we conclude that IVOil carries a significant negative risk premium in the post-financialization period. 


\section{Robustness Checks and Further Discussion}

In this section we conduct various robustness checks and explore different aspects of our results. First, we test if $\Delta I V O i l$ contains information not captured by $\Delta V I X$. Second, we check if innovations in (expected) realized volatility based on high-frequency futures returns (and not implied volatility based on options) have implications for the cross-section of returns. Third, we check if the volatility risk premium, defined as the difference between implied volatility and (expected) realized volatility, can predict the cross-section of stock returns. Fourth, we ask if exposure to simple oil futures returns (and not volatility innovations) has cross-sectional return implications. Finally, we look at the industry composition of quintile portfolios from univariate sorting, and we investigate whether our findings are driven by basic industry effects.

\section{$5.1 \quad$ Using $\triangle I V O i l$ Orthogonalized by $\Delta V I X$}

In spite of the efforts we have made so far, one may reasonably wonder to which extent the $\Delta I V O i l$ betas are simply picking up the $\Delta V I X$ effect documented in Ang, Hodrick, Xing and Zhang (2006). To address this issue we first use daily data and orthogonalize $\Delta I V O i l$ by $\Delta V I X$ via the following regression in each month

$$
\Delta I V O i l_{t}=c_{0}+c_{1} \Delta V I X_{t}+e_{t}^{I V O i l}
$$

In the second step, we use the residual $e_{t}^{I V O i l}$ to estimate oil betas on daily stock returns in each month in the usual fashion

$$
R_{i, t}-R_{f, t}=\beta_{0}^{i}+\beta_{M K T}^{i}\left(R_{m, t}-R_{f, t}\right)+\beta_{I V O i l}^{i} e_{t}^{I V O i l}+\varepsilon_{i, t} .
$$

Finally, we sort stocks based on $\beta_{I V O i l}^{i}$ into five portfolios and record the subsequent month's return for each portfolio.

Table 10 contains the results. Comparing with Table 2 we see that orthogonalizing $\triangle I V O i l$ by $\triangle V I X$ changes the sorted returns little. The average return in the postfinancialization period is $-0.66 \%$ in Table 10 and also $-0.66 \%$ in Table 2. The Carhart alpha is $-0.73 \%$ in Table 10 versus $-0.75 \%$ in Table 2 . The average return and alpha are both significant in Table 10 .

We have also calculated the cross-sectional correlation of $\beta_{I V O i l}$ in equation (4) and $\beta_{V I X}$ in equation (9) in each quintile portfolio. The average correlation of $\beta_{I V O i l}$ and $\beta_{V I X}$ are around $1 \%$ in each of the five portfolios and in both sample periods. The low correlations suggest that $\triangle I V O i l$ captures effects that are different from those captured by $\Delta V I X$. 


\subsection{Estimating $\triangle I V O i l$ Beta Allowing for $\Delta V I X$ Beta}

In this subsection we perform a different and complementary robustness exercise aimed at disentangling the effects from oil volatility and $V I X$. In the first stage, we run a trivariate regression each month

$$
R_{i, t}-R_{f, t}=\beta_{0}^{i}+\beta_{M K T}^{i}\left(R_{m, t}-R_{f, t}\right)+\beta_{I V O i l}^{i} \Delta I V O i l_{t}+\beta_{V I X}^{i} \Delta V I X_{t}+\varepsilon_{i, t},
$$

and in the second stage we sort stocks on either $\beta_{I V O i l}^{i}$ or $\beta_{V I X}^{i}$ and record the subsequent month's returns. Table 11 contains the results.

Looking first at the $\Delta V I X$ beta sorts we see that the 5 - 1 returns and alphas are negative in both sample periods but only significant in the pre-financialization period. Looking next at the $\triangle I V O i l$ betas we see that as expected the returns and alphas are close to zero and insignificant in the pre-financialization period. In the post-financialization period the average return is $-0.54 \%$ for $\Delta I V O i l$ betas versus $-0.19 \%$ for $\Delta V I X$ betas. The Carhart alpha for $I V O i l$ is $-0.61 \%$ versus $-0.27 \%$ for $V I X$. The $\Delta I V O i l$ beta return is significant but alpha is not. Comparing the return magnitudes of the $\Delta I V O i l$ betas in Table 11 with the benchmark numbers in Table 2 we see that they are very similar.

\subsection{Using Realized Volatility Measures}

The next question we ask is if options indeed capture volatility better than more standard return-based volatility measures? To this end we consider realized volatility $(R V)$ calculated from high-frequency intraday oil futures prices which we obtain from TickData. We then test if innovations in expected realized volatility at the one-month horizon have implications for the cross-section of expected stock returns. To get daily $R V$, we use the two-scale estimation approach proposed Zhang, Mykland and Ait-Sahalia (2005), which Andersen, Bollerslev and Meddahi (2011) have shown to be robust to the impact of microstructure noise in highfrequency data.

In order to obtain the best possible estimate of expected 21-business-day realized volatility, we estimate heterogeneous autoregressive $(H A R)$ regressions of the form

$$
R V_{t}=a_{0}+a_{D} R V_{t-1: t}+a_{W} R V_{t-5: t}+a_{M} R V_{t-21: t}+e_{t}^{R V}
$$

where $R V_{t-1: t}, R V_{t-5: t}$, and $R V_{t-21: t}$ denote the most recent daily, weekly, and monthly realized volatility, respectively. Then we use the HAR regression to predict realized volatility for the next 21 trading days, $E_{t}\left[R V_{t+1: t+21}\right]$. The $H A R$ forecasting regressions are proposed by Corsi (2009) and have been used in many studies including Busch, Christensen, and Nielsen (2011). We estimate the $H A R$ regression coefficients on rolling samples of 250 days. 
We are now ready to run the following regressions at the end of each month on daily returns and innovations in expected $R V$

$$
R_{i, t}-R_{f, t}=\beta_{0}^{i}+\beta_{M K T}^{i}\left(R_{m, t}-R_{f, t}\right)+\beta_{R V}^{i} \Delta E_{t}[R V]+\varepsilon_{i, t} .
$$

As before, we sort stocks into quintiles based on $\beta_{R V}$, form five value-weighted portfolios at the end of each month, and record the daily returns of each quintile portfolio during the following month.

Table 12 reports the results. We find that the average spread returns and alphas are small and insignificant in both 1990 - 2004 and 2005 - 2012. As additional robustness checks (not reported), we proxy for changes in expected realized volatility using daily changes in $R V_{t-1, t}$ as well as daily changes in $R V_{t-21: t}$. Again, we find no evidence of cross-sectional return predictability in neither the pre- nor post- financialization periods.

We conclude that option-implied volatility contains information about the cross-section of equity returns that is not readily extracted from return-based volatility measures. One potential explanation is that option-implied volatility contains information about the oil volatility risk premium which we investigate next.

\subsection{Using the Oil Volatility Risk Premium}

So far we have shown that changes in risk-neutral oil volatility have cross-sectional implications for stock returns, whereas changes in realized oil volatility from futures returns do not. These results raise the question if exposure to the volatility risk premium embedded in oil options drives stock returns?

To answer this question we define the volatility risk premium as

$$
V R P_{t}=I V O i l_{t}-E_{t}[R V]
$$

We again apply the $H A R$ approach to forecast expected $R V$ for the next 21 trading days to match the horizon of IVOil. We then run the following regressions at the end of each month on daily returns during the month,

$$
R_{i, t}-R_{f, t}=\beta_{0}^{i}+\beta_{M K T}^{i}\left(R_{m, t}-R_{f, t}\right)+\beta_{V R P}^{i} \Delta V R P_{t}+\varepsilon_{i, t} .
$$

Then we sort stocks into quintiles based on $\beta_{V R P}$, form five value-weighted portfolios, and record the daily returns of each quintile portfolio during the following month.

Table 13 reports the results. We find that the average spread returns are negative and significant in 2005 - 2012. Alphas are negative but insignificant. Although both spread returns and alphas are smaller in magnitude than the numbers in Table 2, they follow a similar decreasing pattern. Table 13 thus suggests that option-implied oil volatility is useful because it contains information about the oil volatility risk premium. 


\subsection{Portfolio Sorts on Oil Return Exposure}

So far we have documented that a stock's exposure to innovations in option-implied oil price volatility is an important determinant of its expected return. A natural question arises: Do stocks' exposure to oil price returns themselves generate a spread in expected returns? We address this question by running the following regression on daily returns at the end of each month,

$$
R_{i, t}-R_{f, t}=\beta_{0}^{i}+\beta_{M K T}^{i}\left(R_{m, t}-R_{f, t}\right)+\beta_{\text {Oil Ret }}^{i} \text { Oil Ret } \text { Re }_{t}+\varepsilon_{i, t},
$$

where $\mathrm{Oil} \mathrm{Ret}_{t}$ is the daily return computed from the closest-to-maturity futures prices. We then sort stocks into 5 quintiles based on $\beta_{\text {Oil Ret }}$ with the first quintile having the lowest beta and the fifth having the highest beta. We form five value-weighted portfolios at the end of each month and record the daily returns of each quintile portfolio during the following month. We repeat the procedure by rolling the beta estimation window forward one month at a time. Table 14 reports the average pre-ranking beta and post-ranking monthly returns (in \%) for each quintile portfolio as well as the monthly alpha (in \%) based on the Carhart four-factor model. We report Newey-West t-statistics for monthly returns with 12 lags and for daily Jensen's alpha with 21 lags.

The results in Table 14 show that for the 2005 - 2012 period the oil return based stock return spread is $0.33 \%$ per month with a corresponding alpha of $0.32 \%$. However, neither the average return nor the Carhart alpha is significant. The spread return and alpha are also insignificant in the 1990 - 2004 sample. For both subperiods, neither the average return nor the Carhart alpha significantly increases or decreases with exposures to $\beta_{\text {Oil Ret }}$. The results in Tables 2 and 14 suggest that oil price risk is more relevantly captured by option implied volatility (as done in Table 2) than simple oil returns (as done in Table 14).

Given the results from oil returns, realized volatility, and volatility risk premium, we conclude that our option-implied volatility measure gives the clearest cross-sectional differences in expected returns: Stocks with large positive oil price volatility betas are good hedges for deteriorating funding liquidity and broad economic conditions, command a high price, and thus earn low expected returns on average.

\subsection{Industry Composition of Oil Volatility Portfolios}

The results so far have shown that stocks' exposure to changes in oil price volatility create a significant spread in the cross-section of average returns. One may reasonably wonder if this effect is simply capturing different exposures to oil volatility risk across industries. We now explore this question. 
First, we regress daily stock returns on $\triangle I V O i l$ using the bivariate regression in equation (4) and sort stocks into 5 portfolios at the end of each month. We track the industry to which each firm belongs using the Fama-French 49 industry portfolio classification. We then compute the average (across time) fraction of firms from each industry in the low and high $\triangle I V O i l$-exposure quintile portfolios for the periods $1990-2004$ and $2005-2012$. By construction the average (across industries) percent of firms in each portfolio equals $20 \%$.

Figure 9 reports the average percent of firms from each industry in portfolio 1 (top panel) which contains the lowest $\beta_{\text {IVOil }}$ stocks and in portfolio 5 (bottom panel) which contains the highest $\beta_{\text {IVOil }}$ stocks. We report the pre- and post-financialization periods separately using the asterisk $(*)$ and circle (o) markers, respectively. A mark below the solid line (representing the average $20 \%$ ) suggests that the particular industry is less affected by oil volatility risk than others. Industries with increasing representation going from the pre- to the postfinancialization period are shown in black font and industries with decreasing representation are shown in grey font. Interestingly, when comparing the low and high beta portfolios, we find that industries that are over-represented in the low-beta portfolio also tend to be over-represented in the high-beta portfolio. The most strongly over-represented industries in portfolio 1 and 5 include precious metals (gold), non-metallic and industrial metal mining (mines), coal, and petroleum and natural gas (oil). The most strongly under-represented industries in portfolio 1 and 5 are tobacco products (smoke), utilities (util), and trading (fin). If we compare the pre and post- financialization periods, industries including nonmetallic and industrial metal mining (mines), coal, petroleum and natural gas (oil), banking (banks), real estate (rlest) become more exposed to oil volatility risk after financialization. In particular, banking (banks) experienced the largest increase in oil volatility risk exposure in the high-beta portfolio among all industries, as shown in the lower panel of Figure 9. The increased level of exposure of banking and real estate industries to oil volatility risk provides an additional aspect of the financialization of commodities.

Figure 9 shows that the same industries tend to be over-represented in quintile portfolios 1 and 5. This suggests that the cross-sectional pattern in expected stock return that we find in Section 2.2 is not driven by plain industry effects, but instead by intra-industry differences across firms in their exposure to oil volatility risk.

\section{Conclusion}

The sharp increase in the popularity of commodity investing and the availability of new commodity-linked securities have brought sweeping changes to futures price dynamics, volatility and option prices. We focus on arguably the most important commodity, crude oil, and 
test if stocks' exposure to oil volatility risk is an important factor in driving the cross-section of expected returns.

First, when sorting stocks based on their exposure to oil volatility risk, we find significant results after the financialization of commodity markets. The spread is significant and robust to the standard Carhart four factors. Stocks with a negative beta with shocks to optionimplied oil volatility, $\triangle I V O i l$ earn a high return (positive alpha) and stocks with positive beta with $\triangle I V O i l$ earn a low return (negative alpha). The difference in average returns between the quintile of stocks with most negative exposure and the quintile of stocks with the most positive exposure to oil volatility is $0.66 \%$ per month. When positive shocks to oil volatility signal deteriorating market conditions as well as funding conditions of financial intermediaries then this is sensible: Stocks that perform poorly during deteriorating market and funding conditions need to earn a higher average expected return (and positive alpha) to be attractive to investors and vice versa.

Second, when investigating its time-series properties, we find that oil volatility is a strong predictor of future returns and volatility in the overall stock market after the financialization of commodity markets, which indicates its importance as an economic state variable. We also document that oil volatility is strongly associated with various measures of funding constraints of financial intermediaries. Our results suggest that oil price uncertainty impacts the stock market through this economic channel.

Third, we document that $\triangle I V O i l$ exhibits risk factor characteristics. After the financialization of commodity markets, the return and Sharpe ratio of a hedge portfolio based on oil volatility risk are higher than those of standard size, value, and momentum risk factors. Oil volatility risk carries a risk premium of $-0.60 \%$ per month when using our sorted portfolios. The risk premium is robust to variations in the empirical design and alternative asset portfolios. Overall, we argue that oil volatility risk has important implications for the cross-section of expected stock returns.

Motivated by Merton's (1973) ICAPM model we have argued that $\triangle I V O i l$ creates spreads in expected returns in the cross-section because it predicts future lower market return and higher market volatility at the monthly frequency. Going forward, it would be of significant interest to explore the economic mechanism further. Ready (2013) classifies oil prices changes into supply or demand shocks. Doing so would be interesting for oil volatility shocks as well.

Our paper provides evidence that a direct and model-free measure of oil price uncertainty has significant pricing implications across stocks. Preliminary results, which we have not reported, show that option-implied volatility from other commodities such as gold and copper do not drive the cross-section of expected stock returns. Furthermore, the economic linkages 
between option-implied volatility, the stock market, and funding constraints of financial intermediaries are much weaker for gold and copper than for oil. Option-implied oil volatility thus appears to be special among the important commodity volatilities. Investigating pricing kernels that incorporate both market risk and oil volatility risk might be helpful to further our understanding of the economic mechanisms by which oil volatility shocks predict stock returns in the cross section. 


\section{References}

Acharya, V., Lochstoer, L., Ramadorai, T., 2013. Limits to arbitrage and hedging: Evidence from commodity markets. Journal of Financial Economics 109, 441-465.

Andersen, T., Bollerslev, T., Meddahi, N., 2011. Realized volatility forecasting and market microstructure noise. Journal of Econometrics 160, 220-234.

Ang, A., Hodrick, R. J., Xing, Y., Zhang, X., 2006. The cross-section of volatility and expected returns. Journal of Finance 61, 259-299.

Adrian, T., Etula, E., Muir, T., 2014. Financial intermediaries and the cross-section of asset returns. Journal of Finance, forthcoming.

Baker, S. D., 2012. The financialization of storable commodities. Working paper, Carnegie Mellon University.

Baker, S. D., Routledge. B. R., 2012. The price of oil risk. Working paper, Carnegie Mellon University.

Bakshi, G., Chen, Z., 1996. Inflation, asset prices, and the term structure of interest rates in monetary economies. Review of Financial Studies 9, 241-275

Bakshi, G., Kapadia, N., Madan, D., 2003. Stock return characteristics, skew laws, and the differential pricing of individual equity options. Review of Financial Studies 16, 101-143.

Bakshi, G., Madan, D., 2000. Spanning and derivative security valuation. Journal of Financial Economics 55, 205-238.

Bali, T., Zhou, H., 2013. Risk, uncertainty, and expected returns. Working Paper, Georgetown University.

Bansal, R., Kiku, D., Shaliastovich, I., Yaron, A., 2014. Volatility, the macroeconomy, and asset prices, Journal of Finance 69, 2471-2511.

Barone-Adesi, G., Whaley, R., 1987. Efficient analytic approximation of American option values. Journal of Finance 42, 301-320.

Barsky, R., Kilian, L., 2004. Oil and the macroeconomy since the 1970s. Journal of Economic Perspectives 18, 115-134.

Basak, S., Pavlova, A., 2013. A model of financialization of commodities. Working Paper, London Business School. 
Bloom, N., 2009. The impact of uncertainty shocks. Econometrica 77, 623-685.

Bollerslev, T., Tauchen, G. , Zhou, H., 2009. Expected stock returns and variance risk premia. Review of Financial Studies, 22, 4463-4492.

Boons, M., Roon, F., Szymanowska, M., 2013. The stock market price of commodity risk. Working Paper, Tilburg University.

Boyson, N., Stahel, C. W., Stulz, R. M., 2010. Hedge fund contagion and liquidity shocks, Journal of Finance 65, 1789-1816.

Brunnermeier, M., Pedersen, L., 2009. Market liquidity and funding liquidity, Review of Financial Studies 22, 2201-2238.

Busch, T., Christensen, B. J., Nielsen, M., 2011. The role of implied volatility in forecasting future realized volatility and jumps in foreign exchange, stock, and bond markets. Journal of Econometrics 160, 48-57.

Buyuksahin, B., Haigh M. S., Harris, J. H., Overdahl, J. A., Robe, M. A., 2011. Fundamentals, trader activity and derivative pricing. Working paper, Commodity Futures Trading Commission (CFTC).

Carhart, M., 1997. On persistence of mutual fund performance. Journal of Finance 52, 57-82.

Carlson, M., Khokher, Z., Titman, S., 2007. Equilibrium exhaustible resource price dynamics. Journal of Finance 62, 1663-1703.

Carr, P., Madan, D., 2001. Optimal positioning in derivative securities. Quantitative Finance $1,19-37$.

Casassus, J., Collin-Dufresne, P., Routledge, B. R., 2009. Equilibrium commodity prices with irreversible investment and non-linear technologies. Working paper, Carnegie Mellon University.

Chang, B.Y., Christoffersen, P., Jacobs, K., 2013. Market skewness risk and the cross section of stock returns. Journal of Financial Economics 107, 46-68.

Chen, N.-F., Roll, R., Ross, S., 1986. Economic forces and the stock market. Journal of Business 59, 383-403.

Cheng, I.-H., Xiong, W., 2013. The financialization of commodity markets. Working Paper, Dartmouth College. 
Chiang, E., Hughen, K, Sagi, J., 2013. Estimating oil risk factors using information from equity and futures markets. Journal of Finance, forthcoming.

Cochrane, J., 2005. Asset pricing. Princeton University Press.

Conrad, J., Dittmar, R., Ghysels, E., 2013. Ex ante skewness and expected stock returns. Journal of Finance 68, 85-124.

Corsi, F., 2009. A simple approximate long memory model of realized volatility. Journal of Financial Econometrics 7, 174-196.

Duan, J. C., Wei, J., 2009. Systematic risk and the price structure of individual equity options. Review of Financial Studies 22, 1981-2006.

Fama, E. F., French, K. R., 1988. Permanent and temporary components of stock prices. Journal of Political Economy 92, 246-273.

Fama, E. F., French, K. R., 1993. Common risk factors in the returns on stocks and bonds. Journal of Financial Economics 33, 3-56.

Fama, E. F., MacBeth, J. D., 1973. Risk, return and equilibrium: empirical tests. Journal of Political Economy 81, 607-636.

Ferson, W., Harvey, C., 1993. The risk and predictability of international equity returns. Review of Financial Studies 6, 527-566.

Frazzini, A., Pedersen, L., 2014. Betting against beta, Journal of Financial Economics 111, $1-25$.

Fontaine, J.-S., Garcia R., 2012. Bond liquidity premia. Review of Financial Studies 25, 1207-1254.

Hamilton, J. D., 2008. Oil and the macroeconomy. The New Palgrave Dictionary of Economics. Palgrave Macmillan.

Hamilton, J. D., Wu, J. C., 2012. Effects of index-fund investing on commodity futures prices. International Economic Review, forthcoming.

Hamilton, J. D., Wu, J. C., 2013. Risk premia in crude oil futures prices. Journal of International Money and Finance, forthcoming.

Hansen, L. P., Hodrick R. J., 1980. Forward exchange rates as optimal predictors of future spot rates: an econometric analysis. Journal of Political Economy 88, 829-853. 
Henderson, B., Pearson, N., Wang, L., 2012. New evidence on the financialization of commodity markets. Working paper, University of Illinois at Urbana-Champaign.

Huang, R., Masulis, R., Stoll, H., 1996. Energy shocks and financial markets. Journal of Futures Markets 16, 1-27.

Jones, C., Kaul, G., 1996. Oil and the stock markets. Journal of Finance 51, 463-491.

Kellogg, R., 2014. The effect of uncertainty on investment: evidence from Texas oil drilling. American Economic Review 104, 1698-1734.

Kilian, L., 2008. The economic effects of energy price shocks. Journal of Economic Literature 46, 871-909.

Kilian, L., Park, C., 2009. The impact of oil price shocks on the U.S. stock market. International Economic Review 50, 1267-1287.

Kogan, L., Livdan, D., Yaron, A., 2009. Oil futures prices in a production economy with investment constraints. Journal of Finance 64, 1345-1375.

Merton, R., 1973. An intertemporal capital asset pricing model. Econometrica 41, 867-887.

Newey, W. K., West, K. D., 1987. A simple, positive semi-definite, heteroskedasticity and autocorrelation consistent covariance matrix. Econometrica 55, 703-708.

Pastor, L., Stambaugh, R. F., 2003. Liquidity risk and expected stock returns, Journal of Political Economy 111, 642-685.

Ready, R., 2014. Oil consumption, economic growth, and oil futures: a fundamental alternative to financialization. Working paper, University of Rochester.

Ready, R., 2013. Oil prices and the stock market. Working paper, University of Rochester.

Robe, M., Wallen, J., 2014. Fundamentals, Derivatives Market Information and Oil Price Volatility. Working paper, American University.

Ross, S. A., 2005. Neoclassical Finance. Princeton University Press.

Schwert, W., 1989. Why does stock market volatility change over time? Journal of Finance 44, 1115-1153.

Singleton, K., 2014. Investor flows and the 2008 boom/bust in oil prices. Management Science $60,300-318$. 
Tang, K., Xiong, W., 2012. Index investing and the financialization of commodities. Financial Analysts Journal 68, 54-74.

Trolle, A., Schwartz, E., 2009. Unspanned stochastic volatility and the pricing of commodity derivatives. Review of Financial Studies 22, 4423-4461.

Xing, Y., Zhang, X., Zhao, R., 2010. What does the individual option volatility smirk tell us about future equity returns? Journal of Financial and Quantitative Analysis 45, 641-662.

Zhang, L., Mykland, P., Ait-Sahalia, Y., 2005. A tale of two time scales: determining integrated volatility with noisy high-frequency data. Journal of the American Statistical Association, 100, 1394-1411. 
Figure 1: Open Interest and Trading Volume in Crude Oil Futures and Options
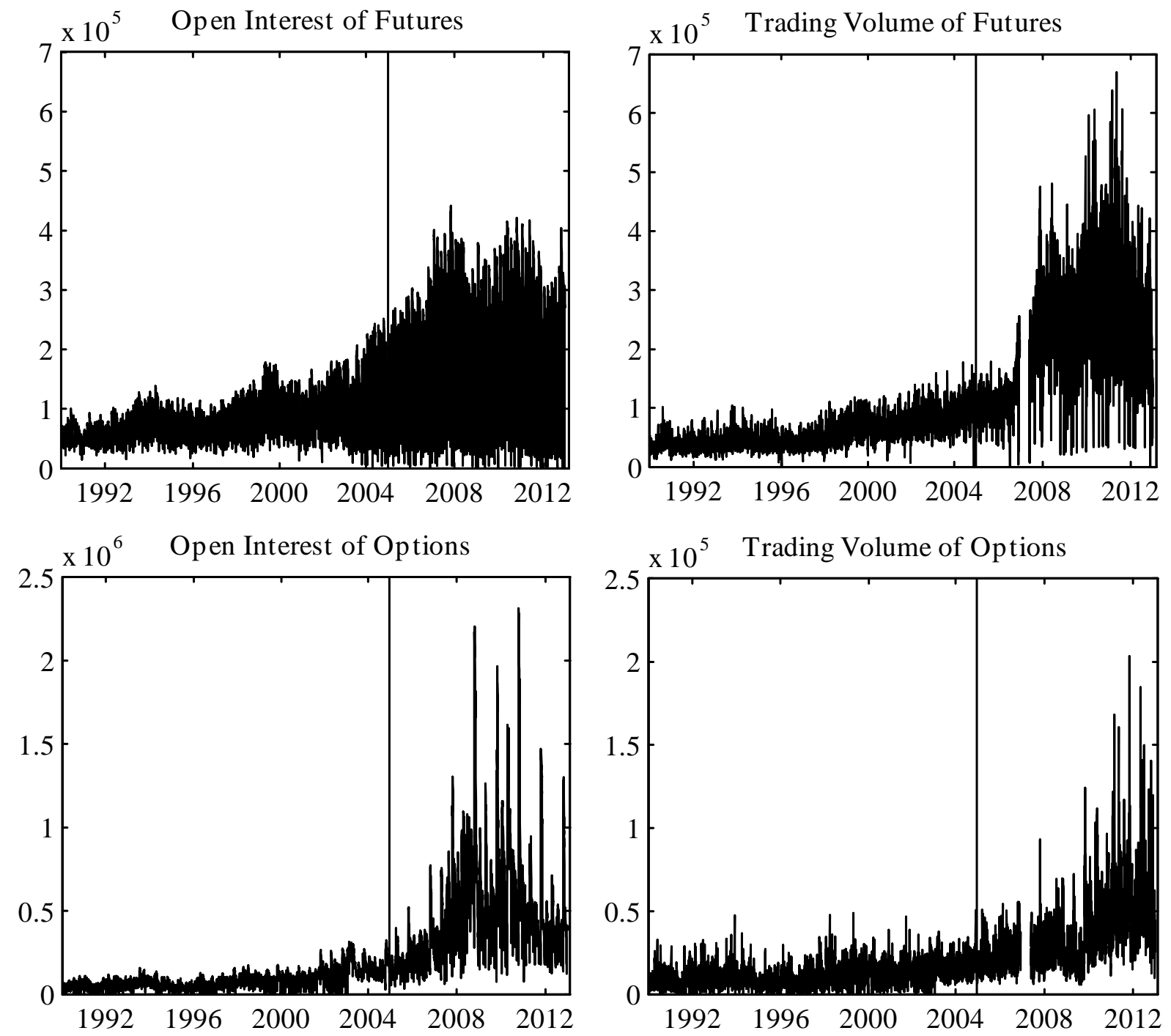

Notes: The top panels in the figure show open interest and trading volume in the closestto-maturity crude oil futures contracts traded on the CME. The bottom panels show open interest and trading volume of options written on the closest-to-maturity futures contracts. Futures (options) trading volume data are not available from December 15, 2006 to May 21, 2007 (December 1, 2006 to May 21, 2007 ) when the CME group converted data from the NYMEX database. The futures and option price and open interest data are available throughout the period. The vertical line represents January 3, 2005. The full sample covers January 2, 1990 to December 31, 2012. 
Figure 2: Oil Price Volatility, Oil Futures Price and S\&P 500 Index Oil Volatility (\%)

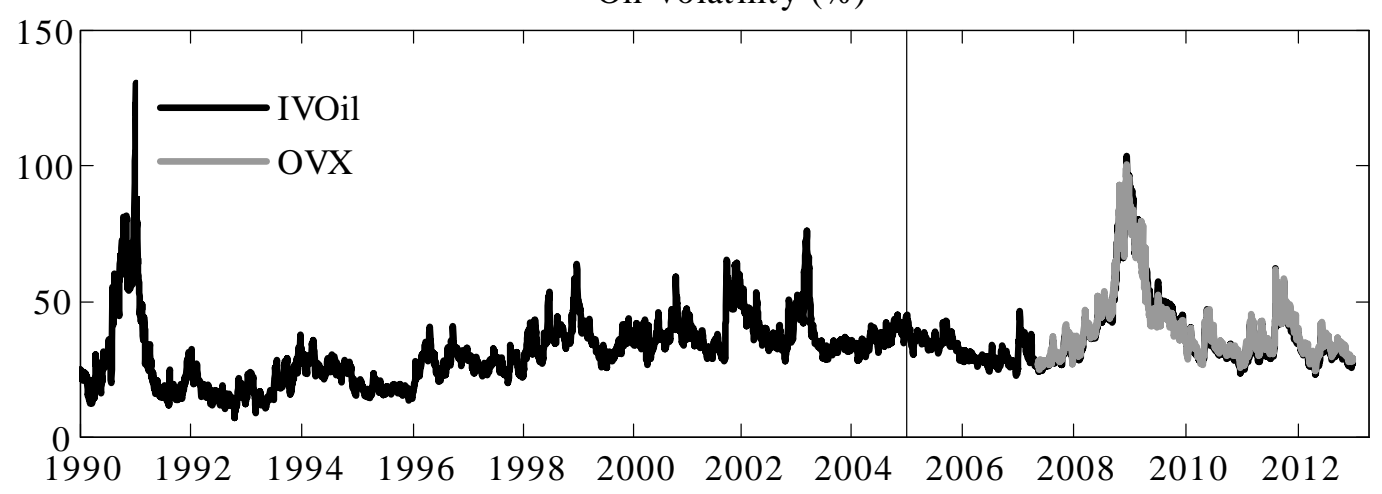

Closest-to-Maturity Futures Price (\$)

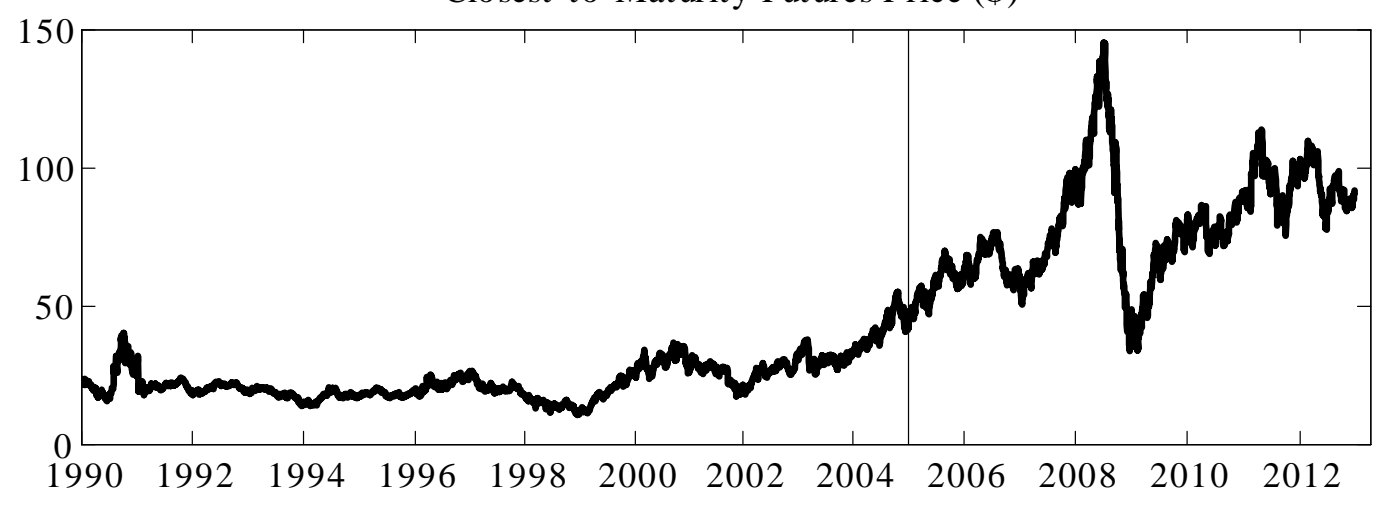

S\&P 500

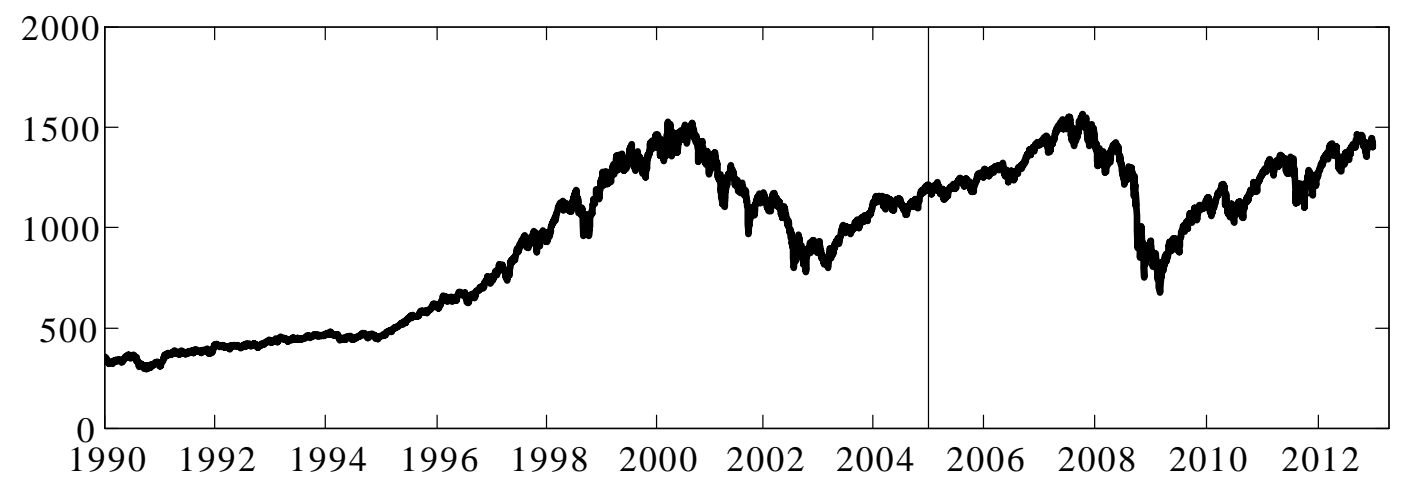

Notes: The top panel in the figure shows the daily option-implied oil price volatility, IVOil (in black), inferred from crude oil futures options with 30 day-to-maturity and CBOE's Crude Oil Volatility Index, $O V X$ (in grey). The middle and bottom panels show the closest-tomaturity oil futures price and the S\&P 500 index, respectively. The vertical line represents January 3, 2005. The full sample covers January 2, 1990 to December 31, 2012. 
Figure 3: Autocorrelation of Option Implied Oil Volatility and Its First Difference
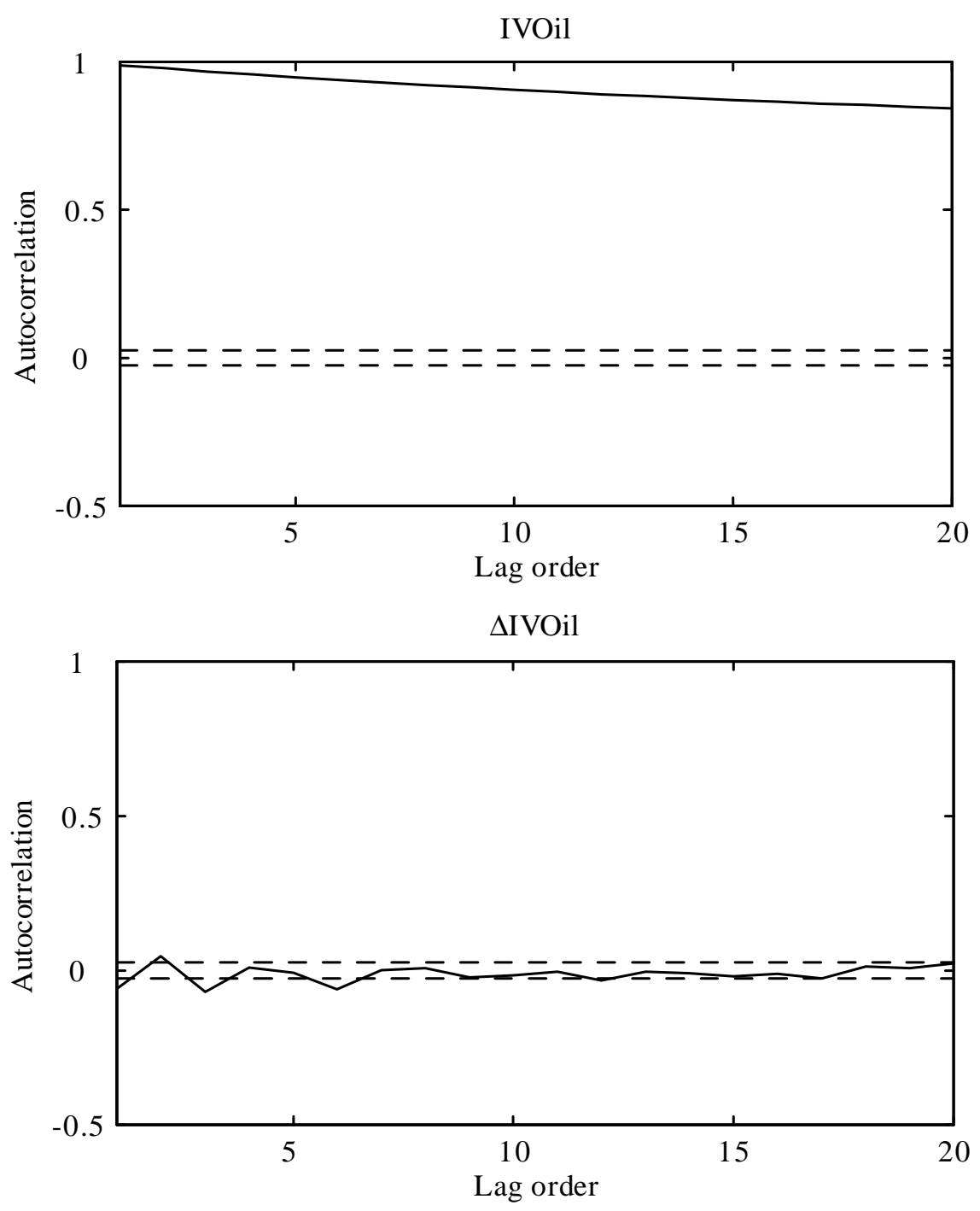

Notes: In the top panel we plot the sample autocorrelation of IVOil, and in the bottom panel the autocorrelation of the first difference, $\Delta I V O i l$. The horizontal dashed lines denote the Bartlett 95\% confidence band. The sample covers January 2, 1990 to December 31, 2012. 
Figure 4: Daily Returns and Volatility Innovations
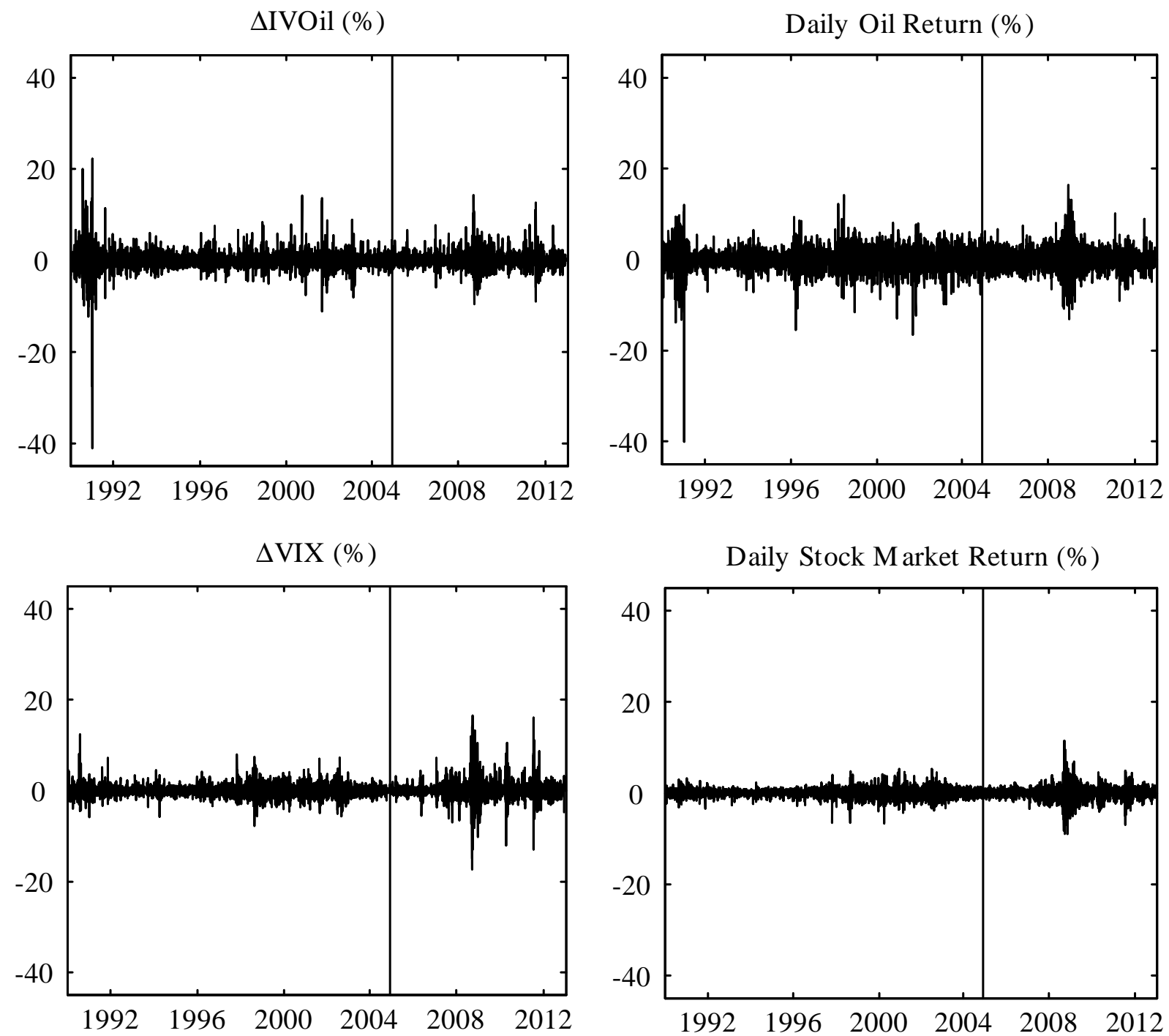

Daily Stock Market Return (\%)

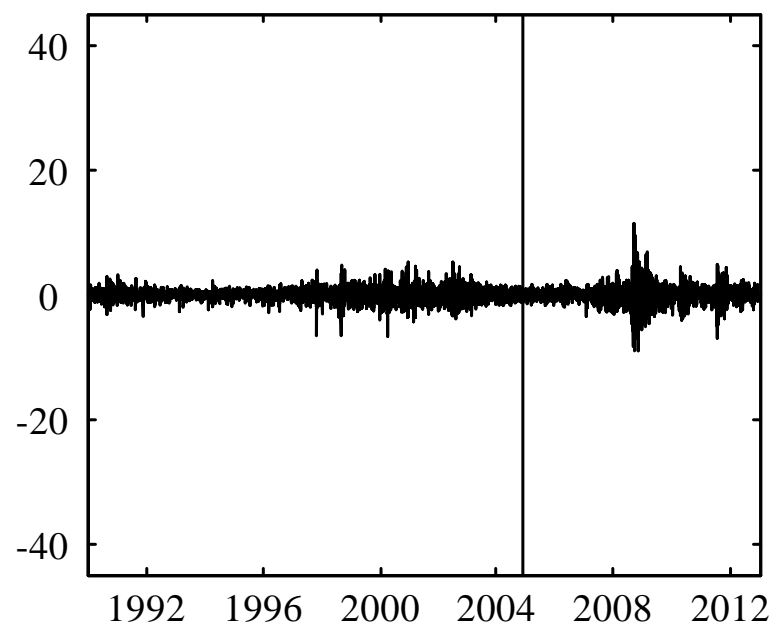

Notes: The figure shows the daily innovation of option-implied oil volatility $\triangle I V O i l$ (topleft), the daily oil return calculated from the closest-to-maturity futures price (top-right), the daily innovation of option-implied stock market volatility $\triangle V I X$ (bottom-left), and the daily stock market return (bottom-right), which is the value-weighted return of all CRSP firms incorporated in the U.S. and is downloaded from the online data library of Ken French. The vertical line represents January 3, 2005. The sample covers January 2, 1990 to December $31,2012$. 
Figure 5: Scatter Plots of Daily Returns and Volatility Innovations
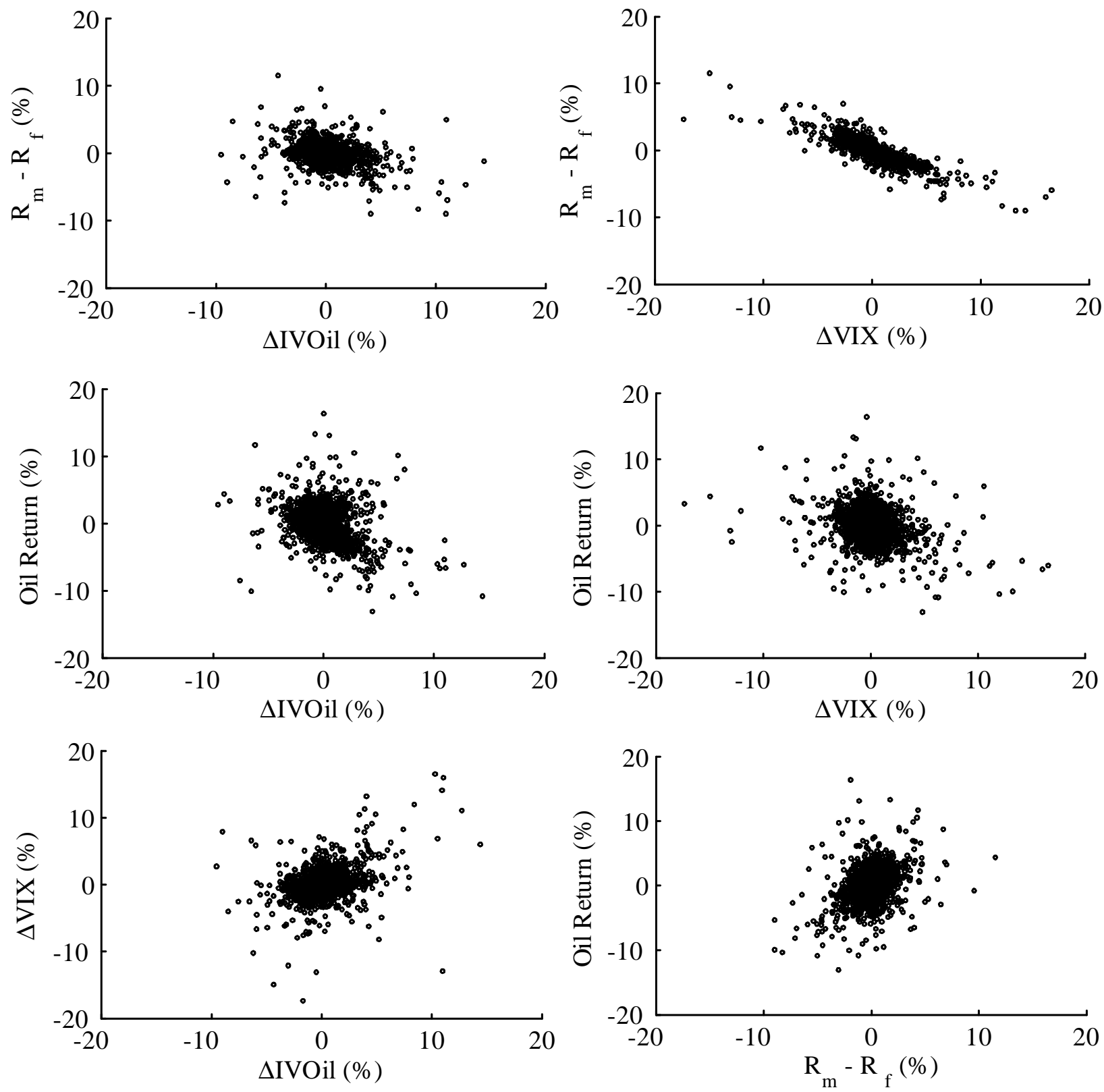

Notes: We report scatter plots of innovations in daily option-implied oil price volatility $(\triangle I V O i l)$, innovations in daily option-implied stock market volatility $(\Delta V I X)$, daily oil return calculated from the closest-to-maturity futures price and daily stock market excess return. The sample covers January 3, 2005 to December 31, 2012. 
Figure 6: Portfolio Returns and Jensen's Alpha from the Carhart 4-Factor Model
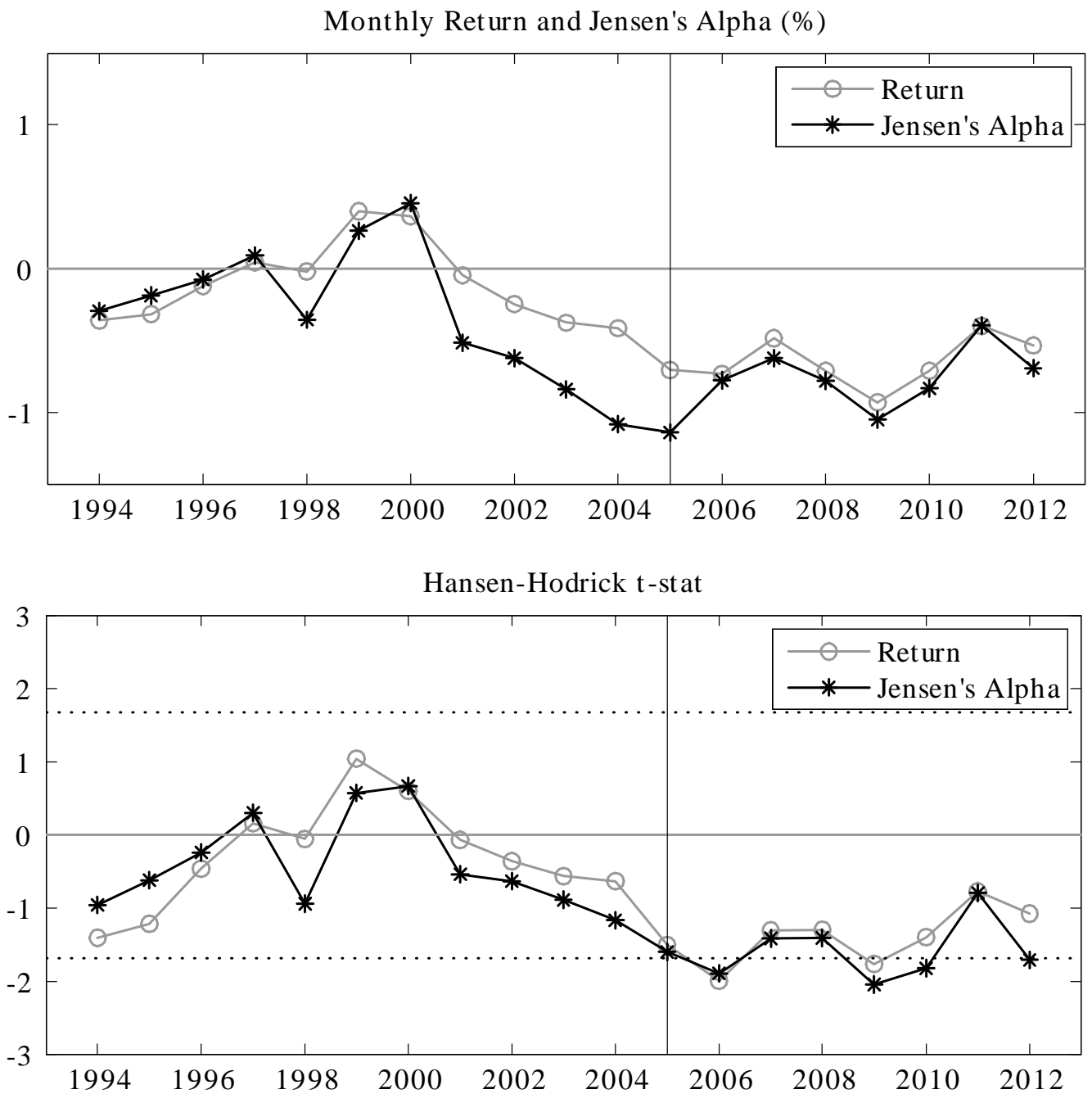

Notes: At the end of each month, we run the following regression on daily returns during the month: $R_{i, t}-R_{f, t}=\beta_{0}^{i}+\beta_{M K T}^{i}\left(R_{m, t}-R_{f, t}\right)+\beta_{I V O i l}^{i} \Delta I V O i l_{t}+\varepsilon_{i, t}$. We then sort stocks into five quintiles based on $\beta_{I V O i l}$, with the first quintile having the lowest beta and the fifth having the highest beta. We form five value-weighted portfolios at the end of each month and record the return of each portfolio during the following month. The figure reports the post-ranking return difference between the fifth and the first portfolios, and the alpha based on the Carhart four-factor model. We use a five-year moving window and we report monthly average return (in \%) and alpha (in \%) computed as the daily value multiplied by 21 . We report Hansen and Hodrick (1980) t-stat with 12 lags for monthly returns and 21 lags for daily alphas. The solid horizontal line is drawn at zero and the dotted lines in the lower panel are drawn at 1.68 and -1.68 . The vertical line is drawn at 2005 . 
Figure 7: Cumulative Returns on Factor Portfolios
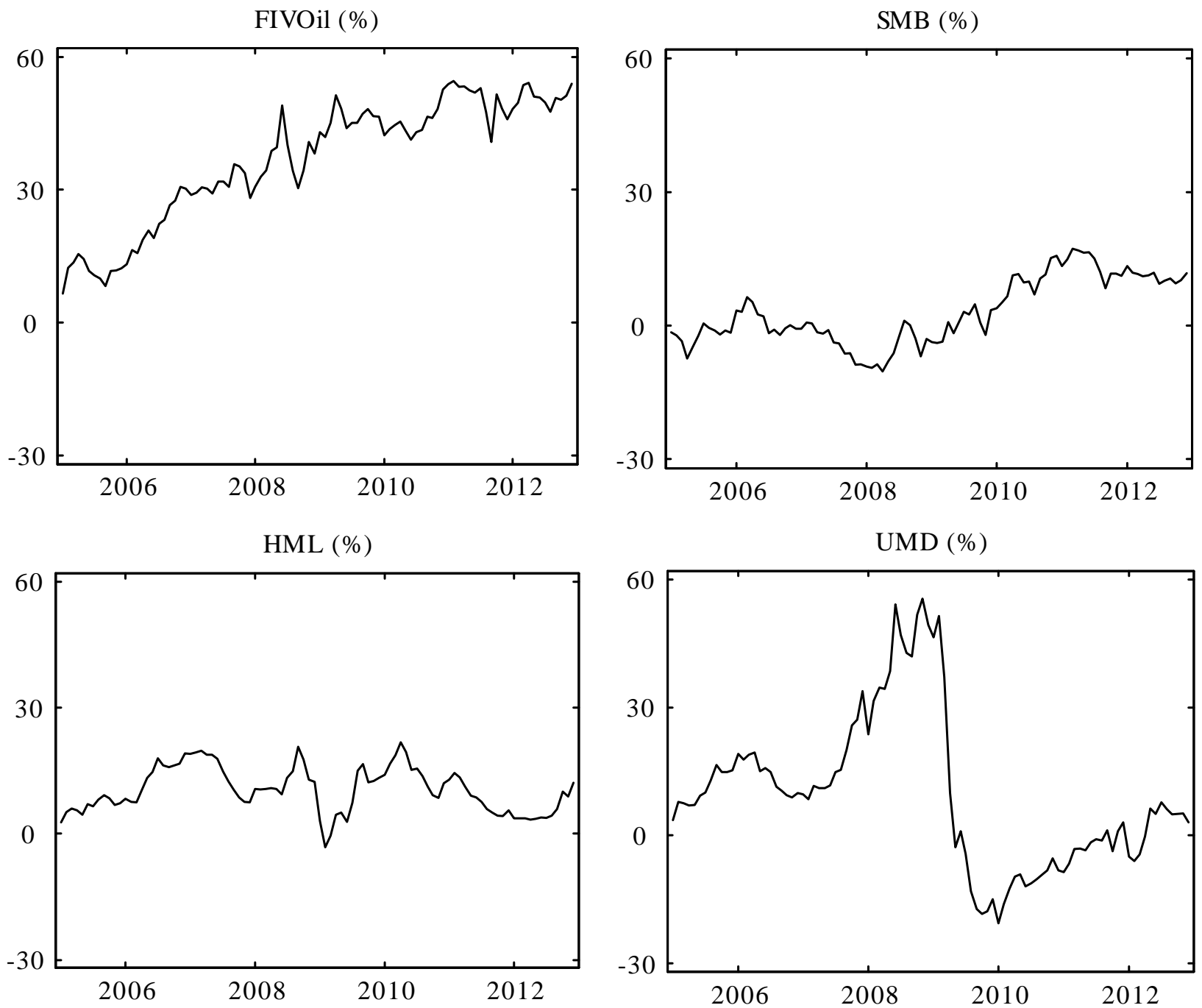

Notes: We plot the (negative of the) cumulative returns on the FIVOil hedge portfolio and the cumulative returns on the standard size $(S M B)$, value $(H M L)$ and momentum $(U M D)$ portfolios from January 2005 to December 2012. The FIVOil hedge portfolio is based on betas from the regression $R_{i, t}-R_{f, t}=\beta_{0}^{i}+\beta_{M K T}^{i}\left(R_{m, t}-R_{f, t}\right)+\beta_{I V O i l}^{i} \Delta I V O i l_{t}+\varepsilon_{i, t}$. 
Figure 8: Cumulative Returns on Volatility Factor Portfolios

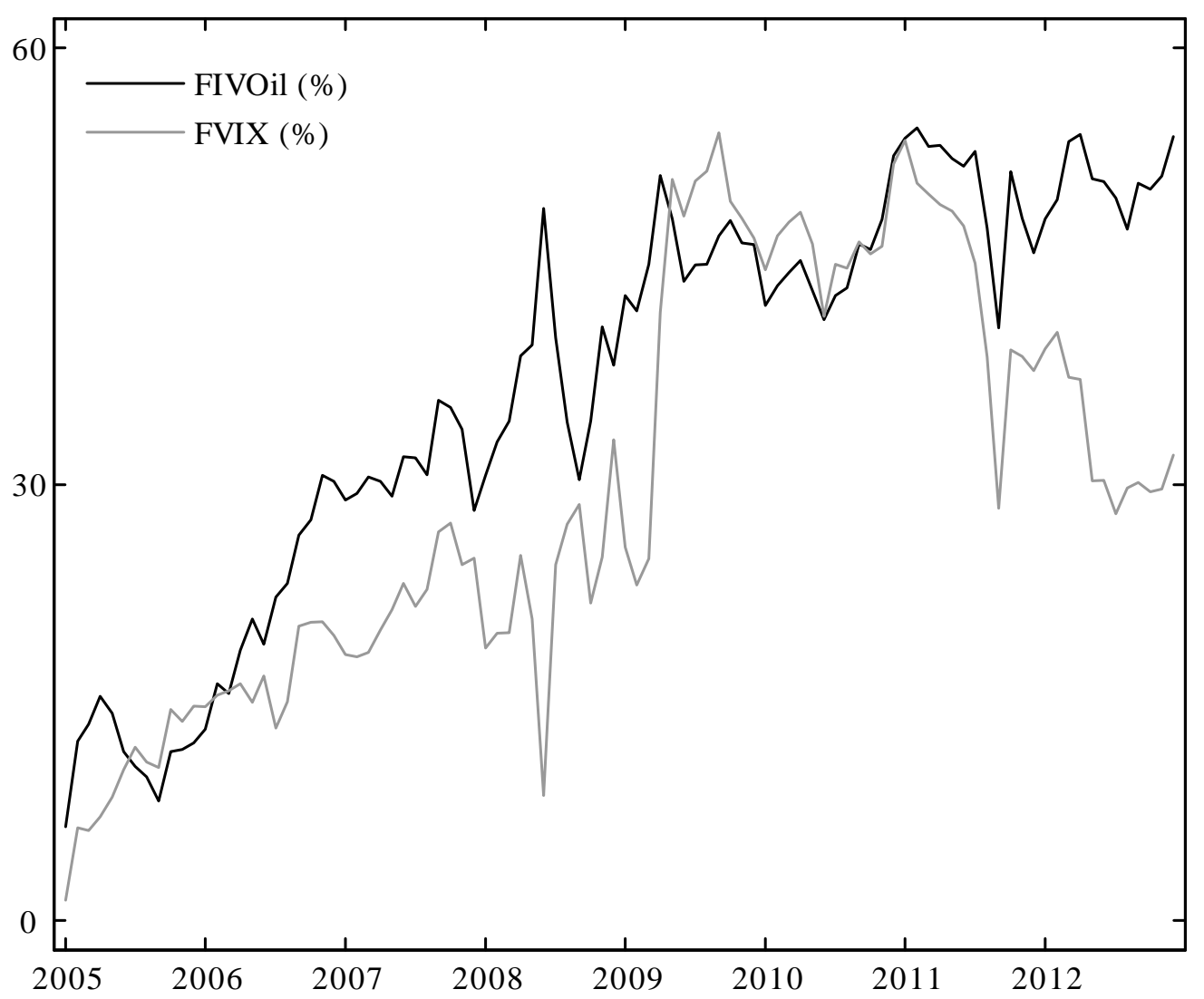

Notes: We plot the (negative of the) cumulative returns on the FIVOil and FVIX hedge portfolios from January 2005 to December 2012. The FIVOil hedge portfolio is based on betas from the regression $R_{i, t}-R_{f, t}=\beta_{0}^{i}+\beta_{M K T}^{i}\left(R_{m, t}-R_{f, t}\right)+\beta_{I V O i l}^{i} \Delta I V O i l_{t}+\varepsilon_{i, t}$. The $F V I X$ hedge portfolio is based on betas from the regression $R_{i, t}-R_{f, t}=\beta_{0}^{i}+\beta_{M K T}^{i}\left(R_{m, t}-\right.$ $\left.R_{f, t}\right)+\beta_{V I X}^{i} \Delta V I X_{t}+\varepsilon_{i, t}$. 

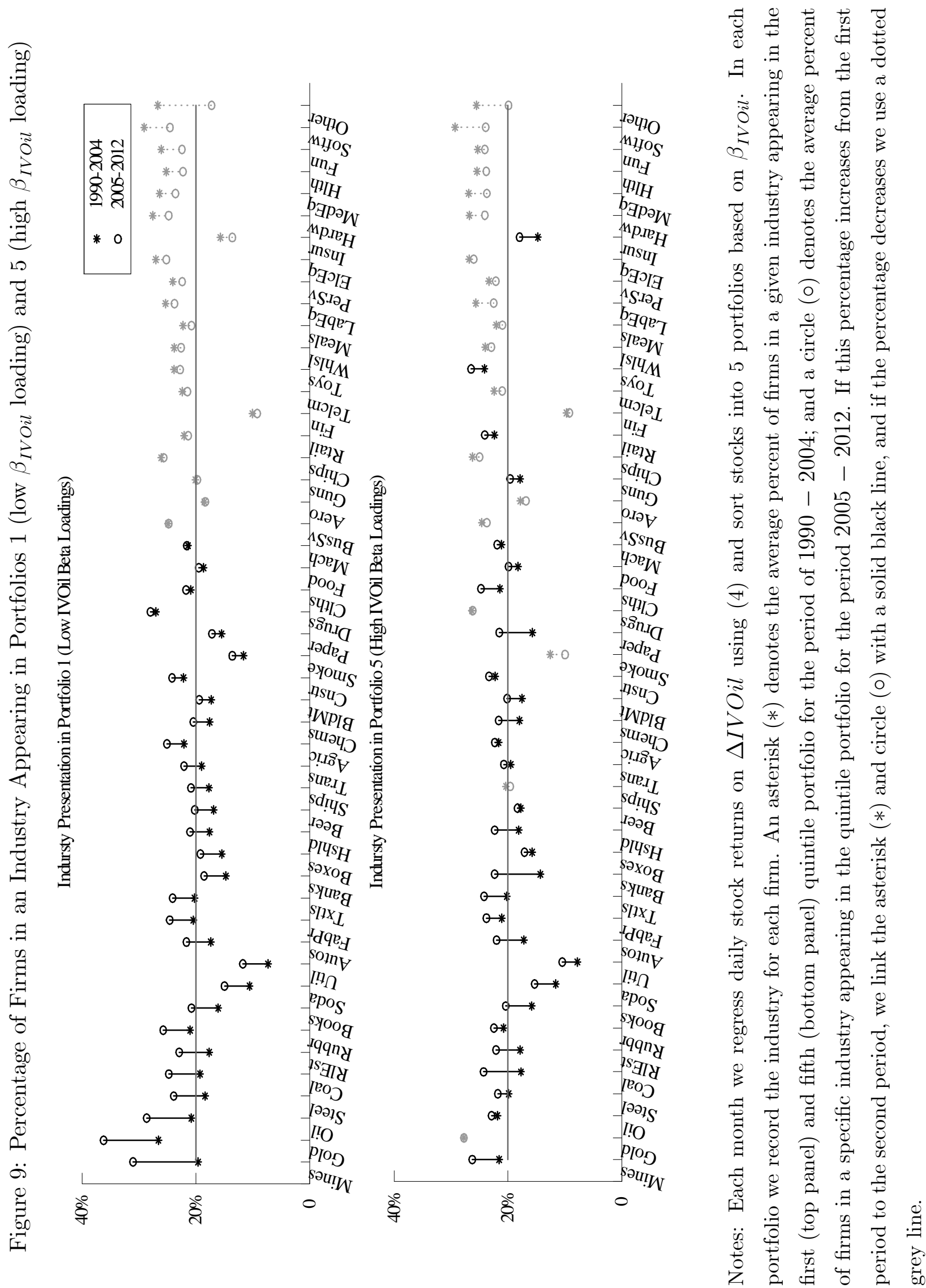
Table 1: Correlation of Risk Factors

\begin{tabular}{c|cccc}
\hline & $\mathrm{R}_{\mathrm{m}}-\mathrm{R}_{\mathrm{f}}$ & Oil Ret & $\Delta$ VIX & $\Delta$ IVOil \\
\hline 1990-2004 & & & & \\
$\mathrm{R}_{\mathrm{m}}-\mathrm{R}_{\mathrm{f}}$ & & -0.06 & -0.72 & -0.07 \\
Oil Ret & & & 0.06 & 0.12 \\
$\Delta$ VIX & & & & 0.14 \\
SMB & -0.17 & 0.06 & 0.14 & -0.03 \\
HML & -0.65 & 0.04 & 0.44 & 0.04 \\
UMD & -0.04 & 0.00 & 0.01 & 0.01 \\
\hline $\mathbf{2 0 0 5 - 2 0 1 2}$ & & & & \\
$\mathrm{R}_{\mathrm{m}}-\mathrm{R}_{\mathrm{f}}$ & & 0.35 & -0.84 & -0.31 \\
Oil Ret & & & -0.28 & -0.31 \\
$\Delta$ VIX & & & & 0.37 \\
SMB & 0.17 & -0.01 & -0.08 & -0.02 \\
HML & 0.44 & 0.16 & -0.31 & -0.10 \\
UMD & -0.43 & -0.09 & 0.26 & 0.11 \\
\hline
\end{tabular}

Notes: We report the correlation between stock market excess returns, oil returns, the innovation of VIX ( $\triangle$ VIX), the innovation of IVOil ( $\triangle$ IVOil), and the standard pricing factors SMB, HML, and UMD. Daily stock market excess return, which is the value-weighted return on all CRSP firms in excess of the risk-free rate, is downloaded from the online data library of Kenneth R. French. Oil return is calculated from daily closest-to-maturity crude oil futures prices. IVOil is the implied volatility from 30-day crude oil option prices. 
Table 2: Sorting on $\triangle$ IVOil Loadings

\begin{tabular}{c|cccccc}
\hline & \multicolumn{7}{|c}{ Quintile Portfolios } \\
& 1 & 2 & 3 & 4 & 5 & $5-1$ \\
\hline 1990-2004 & & & & & & \\
Pre-Ranking Beta & -0.7027 & -0.2343 & -0.0064 & 0.2181 & 0.6792 & 1.3818 \\
Average Return (\%) & 1.14 & 1.10 & 1.12 & 1.15 & 1.06 & -0.08 \\
& & & & & & $(-0.26)$ \\
Carhart Alpha (\%) & 0.30 & 0.13 & 0.12 & 0.06 & -0.02 & -0.32 \\
& & & & & & $(-0.92)$ \\
Post-Ranking Beta & -0.0031 & -0.0019 & 0.0022 & -0.0006 & 0.0016 & 0.0047 \\
Book/Market & 0.82 & 0.73 & 0.76 & 0.74 & 0.83 & \\
Size & 4.10 & 5.10 & 5.15 & 5.11 & 4.13 & \\
Market Share (\%) & 9.07 & 25.58 & 28.54 & 26.63 & 10.18 & \\
\hline 2005-2012 & & & & & & \\
Pre-Ranking Beta & -0.5892 & -0.1967 & -0.0055 & 0.1791 & 0.5585 & 1.1477 \\
Average Return (\%) & 1.08 & 0.93 & 0.58 & 0.53 & 0.42 & -0.66 \\
& & & & & & $\mathbf{( - 2 . 4 9 )}$ \\
Carhart Alpha (\%) & 0.51 & 0.37 & 0.05 & -0.05 & -0.24 & -0.75 \\
& & & & & & $\mathbf{( - 1 . 9 2 )}$ \\
Post-Ranking Beta & -0.0354 & -0.0014 & 0.0014 & 0.0096 & 0.0121 & 0.0475 \\
Book/Market & 0.81 & 0.69 & 0.67 & 0.69 & 0.79 & \\
Size & 5.32 & 6.11 & 6.16 & 6.19 & 5.49 & \\
Market Share (\%) & 11.33 & 23.86 & 26.36 & 25.61 & 12.84 & \\
\hline
\end{tabular}

Notes: At the end of each month, we run the following regression on daily returns during the month:

$$
R_{i, t}-R_{f, t}=\beta_{0}^{i}+\beta_{M K T}^{i}\left(R_{m, t}-R_{f, t}\right)+\beta_{\text {IVOil }}^{i} \Delta I V O i l_{t}+\varepsilon_{i, t} .
$$

We then sort stocks into quintiles based on $\beta_{\text {IVoil }}$ with the first quintile having the lowest beta and the fifth having the highest beta. We form five value-weighted portfolios at the end of each month and record the return of each quintile portfolio during the following month. We repeat the procedure by rolling the beta estimation window forward one month at a time. The table reports the average pre-ranking beta, postranking monthly returns and post-ranking beta for each quintile portfolio, as well as post-ranking Jensen's alpha based on the Carhart four-factor model. We report the monthly alpha computed as the daily alpha multiplied by 21. Newey-West t-statistics with 12 lags for monthly returns and 21 lags for daily alphas are reported in parentheses. T-stats larger than 1.68 in magnitude are reported in boldface. We also report the average book-to-market ratio, size, and market share of each portfolio. 
Table 3: Portfolios Sorted on Sensitivities to $\mathbf{R}_{\mathrm{m}}-\mathbf{R}_{\mathrm{f}}$ and $\Delta$ IVOil

\begin{tabular}{|c|c|c|c|c|c|c|c|c|}
\hline & \multicolumn{4}{|c|}{ Panel A: Sorts on $\beta_{\mathrm{MKT}}$} & \multicolumn{4}{|c|}{ Panel B: Sorts on $\beta_{\text {IVOil }}$} \\
\hline & $\begin{array}{c}\text { Average } \\
\text { Return } \\
(\%, \text { month })\end{array}$ & $\begin{array}{c}\text { Carhart } \\
\text { Alpha } \\
(\%, \text { month })\end{array}$ & $\beta_{\mathrm{MKT}}$ & $\beta_{\text {IVOil }}$ & $\begin{array}{c}\text { Average } \\
\text { Return } \\
(\%, \text { month }) \\
\end{array}$ & $\begin{array}{c}\text { Carhart } \\
\text { Alpha } \\
(\%, \text { month })\end{array}$ & $\beta_{\mathrm{MKT}}$ & $\beta_{\text {IVOil }}$ \\
\hline \multicolumn{9}{|l|}{ 1990-2004 } \\
\hline 1 & 1.26 & 0.19 & -0.90 & -0.02 & 1.22 & 0.22 & 0.62 & -0.74 \\
\hline 2 & 1.11 & 0.12 & 0.04 & -0.01 & 1.19 & 0.25 & 0.63 & -0.25 \\
\hline 3 & 1.08 & 0.02 & 0.52 & -0.01 & 1.00 & 0.05 & 0.62 & -0.01 \\
\hline 4 & 1.10 & 0.04 & 1.11 & -0.01 & 1.06 & 0.04 & 0.62 & 0.23 \\
\hline 5 & 1.02 & 0.14 & 2.36 & 0.00 & 1.09 & -0.05 & 0.63 & 0.72 \\
\hline $5-1$ & -0.24 & -0.05 & & & -0.13 & -0.28 & & \\
\hline NW t-stat & $(-0.46)$ & $(-0.15)$ & & & $(-0.55)$ & $(-1.23)$ & & \\
\hline \multicolumn{9}{|l|}{ 2005-2012 } \\
\hline 1 & 0.52 & 0.08 & -0.21 & -0.16 & 0.97 & 0.38 & 0.86 & -0.62 \\
\hline 2 & 0.69 & 0.20 & 0.44 & -0.05 & 0.80 & 0.24 & 0.89 & -0.20 \\
\hline 3 & 0.63 & 0.09 & 0.86 & -0.02 & 0.65 & 0.13 & 0.91 & 0.00 \\
\hline 4 & 0.74 & 0.10 & 1.32 & 0.02 & 0.53 & 0.00 & 0.94 & 0.19 \\
\hline 5 & 0.84 & 0.14 & 2.15 & 0.12 & 0.47 & -0.12 & 0.96 & 0.55 \\
\hline $5-1$ & 0.32 & 0.07 & & & -0.50 & -0.50 & & \\
\hline NW t-stat & $(0.72)$ & $(0.16)$ & & & $(-2.68)$ & $(-1.47)$ & & \\
\hline
\end{tabular}

Notes: At the end of each month, we run the following regression using daily stock returns

$$
R_{i, t}-R_{f, t}=\beta_{0}^{i}+\beta_{M K T}^{i}\left(R_{m, t}-R_{f, t}\right)+\beta_{I V O i l}^{i} \Delta I V O i l_{t}+\varepsilon_{i, t} .
$$

We then form 25 portfolios using the following procedure. We first sort stocks into 5 quintiles based on $\beta_{M K T}$ with the first quintile having the lowest $\beta_{M K T}$ and the fifth having the highest $\beta_{M K T}$. Within each quintile, we sort stocks based on $\beta_{\text {IV oil }}$ and obtain 25 portfolios. We then group the 25 portfolios into 5 portfolios with exposure to only one factor, i.e. either $R_{m}-R_{f}$ or $\Delta I V O i l$. The table reports the average postranking monthly returns and the post-ranking Carhart four-factor alphas for each group. In parentheses are Newey-West t-statistics using 12 lags for the difference in average monthly returns and 21 lags for the difference in daily alphas between the highest and the lowest exposures. T-stats larger than 1.68 in magnitude are reported in boldface. We report results for the two periods: 1990 to 2004 and 2005 to 2012. 
Table 4: Forecast Regressions for Stock Market Return and Volatility

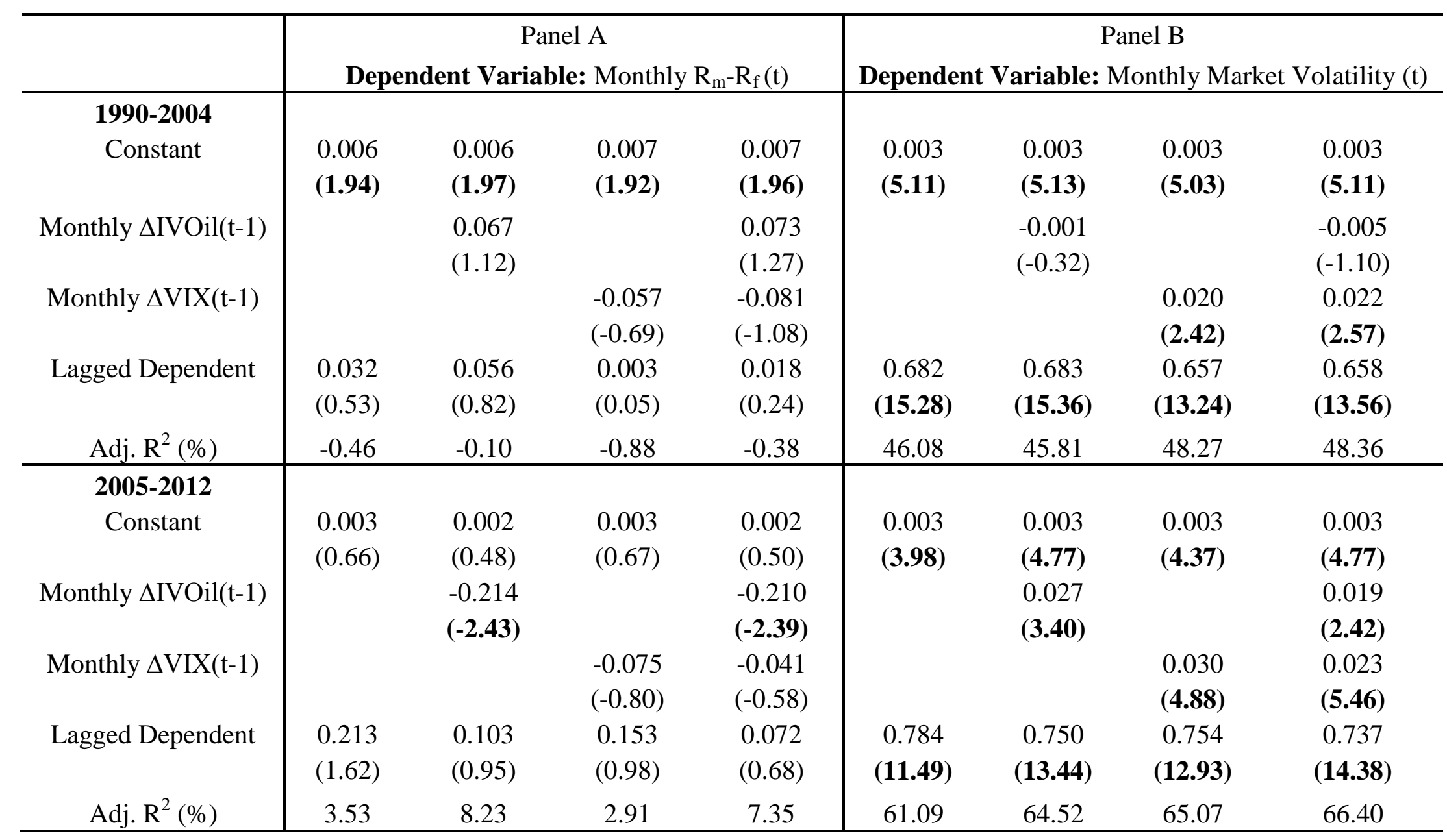

Notes: In Panel A we report forecasting results from regressing monthly market excess returns on lagged returns, lagged monthly innovations in option-implied oil volatility, $\Delta$ IVOil, and lagged monthly innovations in option-implied market volatility, $\triangle$ VIX. In Panel B we report forecasting results for monthly market volatility, which is the standard deviation of daily excess market returns during the month. Newey-West (1987) t-statistics with 12 lags are reported in parentheses. T-stats larger than 1.68 in magnitude are reported in boldface. 
Table 5: Shocks to Oil Volatility and Funding Constraints of Financial Intermediaries

\begin{tabular}{|c|c|c|c|c|c|c|c|c|}
\hline & $\begin{array}{l}(1) \\
\text { Broker- } \\
\text { Dealer } \\
\text { Leverage }\end{array}$ & $\begin{array}{l}(2) \\
\text { Betting } \\
\text { against } \\
\text { Beta }\end{array}$ & $\begin{array}{l}\text { Funding } \\
\text { Liquidity }\end{array}$ & PBI & BANK & $\begin{array}{l}\text { Credit } \\
\text { Spread } \\
\end{array}$ & $\begin{array}{l}\text { TED } \\
\text { Spread }\end{array}$ & $\begin{array}{l}\text { Market } \\
\text { Liquidity }\end{array}$ \\
\hline \multicolumn{9}{|c|}{$\begin{array}{l}\text { Panel A: Contemporaneous regression } \\
\text { 1990-2004 }\end{array}$} \\
\hline & $\begin{array}{l}-0.007 \\
(-0.14)\end{array}$ & $\begin{array}{l}-0.107 \\
(-2.39)\end{array}$ & $\begin{array}{l}0.001 \\
(0.46)\end{array}$ & $\begin{array}{l}-0.108 \\
(-3.49)\end{array}$ & $\begin{array}{l}-1.157 \\
(-3.01)\end{array}$ & $\begin{array}{l}0.004 \\
\mathbf{( 3 . 2 0 )}\end{array}$ & $\begin{array}{l}0.003 \\
\mathbf{( 1 . 9 9 )}\end{array}$ & $\begin{array}{l}-0.000 \\
(-0.18)\end{array}$ \\
\hline Adj. R ${ }^{2}(\%)$ & -1.7 & 1.7 & -0.5 & 2.0 & 1.7 & 3.3 & 2.8 & -0.5 \\
\hline \multicolumn{9}{|l|}{ 2005-2012 } \\
\hline & $\begin{array}{l}-1.001 \\
\mathbf{( - 1 . 9 1 )}\end{array}$ & $\begin{array}{l}-0.192 \\
(-2.41)\end{array}$ & $\begin{array}{l}0.006 \\
(\mathbf{2 . 7 2 )}\end{array}$ & $\begin{array}{l}-0.346 \\
(-5.16)\end{array}$ & $\begin{array}{l}-5.498 \\
(-4.35)\end{array}$ & $\begin{array}{l}0.031 \\
\mathbf{( 3 . 1 6 )}\end{array}$ & $\begin{array}{l}0.015 \\
(\mathbf{2 . 2 3})\end{array}$ & $\begin{array}{l}-0.004 \\
(-4.31)\end{array}$ \\
\hline Adj. R ${ }^{2}(\%)$ & 12.3 & 9.4 & 2.7 & 21.9 & 18.2 & 34.9 & 5.8 & 6.6 \\
\hline \multicolumn{9}{|c|}{$\begin{array}{l}\text { Panel B: Predictive regression } \\
\text { 1990-2004 }\end{array}$} \\
\hline & $\begin{array}{l}0.015 \\
(0.33)\end{array}$ & $\begin{array}{l}-0.066 \\
(-1.19)\end{array}$ & $\begin{array}{l}-0.001 \\
(-0.40)\end{array}$ & $\begin{array}{l}0.043 \\
(0.92)\end{array}$ & $\begin{array}{l}0.523 \\
(0.94)\end{array}$ & $\begin{array}{l}0.001 \\
(0.40)\end{array}$ & $\begin{array}{l}-0.002 \\
(-1.14)\end{array}$ & $\begin{array}{l}-0.000 \\
(-0.23)\end{array}$ \\
\hline Adj. $\mathrm{R}^{2}(\%)$ & -1.7 & 0.3 & -0.4 & -0.2 & -0.1 & -0.4 & 0.1 & -0.6 \\
\hline \multicolumn{9}{|l|}{ 2005-2012 } \\
\hline & $\begin{array}{l}-0.089 \\
(-0.54)\end{array}$ & $\begin{array}{l}-0.106 \\
(-2.16)\end{array}$ & $\begin{array}{l}0.002 \\
(0.48)\end{array}$ & $\begin{array}{l}-0.200 \\
(-\mathbf{3 . 7 8})\end{array}$ & $\begin{array}{l}-3.333 \\
(-2.49)\end{array}$ & $\begin{array}{l}0.017 \\
\mathbf{( 3 . 3 0 )}\end{array}$ & $\begin{array}{l}-0.009 \\
(-0.91)\end{array}$ & $\begin{array}{l}-0.000 \\
(-0.35)\end{array}$ \\
\hline Adj. $\mathrm{R}^{2}(\%)$ & -3.2 & 2.2 & -0.6 & 6.6 & 6.0 & 9.7 & 1.3 & -1.0 \\
\hline
\end{tabular}

Notes: Panel A of this table reports the coefficients $b_{1}$ in the contemporaneous regression of shocks to funding constraints of financial intermediaries on $\Delta \mathrm{IVOil}$ : $\Delta$ Funding $_{t}=b_{0}+b_{1} \Delta I V O i l_{t}+e_{i, t}$. Funding constraint variables include broker-dealer leverage, the betting against beta factor, the funding liquidity factor, the prime broker index (PBI), the Datastream bank index (BANK), the spread between Baa and10year constant maturity Treasury bonds (credit spread), the spread between 3-month LIBOR and 3-month Treasury bonds (TED) and the Pastor and Stambaugh (2003) market liquidity factor. Panel B reports the coefficient $b_{1}^{\prime}$ in the predictive regression $\Delta$ Funding ${ }_{t+1}=b_{0}^{\prime}+b_{1}^{\prime} \Delta I V O i l_{t}+e_{i, t+1}^{\prime}$. We measure shocks on a monthly basis except for broker-dealer leverage which is only available quarterly. NeweyWest t-stats with 12 (6) lags for monthly (quarterly) regressions are reported in parentheses. For brevity we do not report the intercept estimates. T-stats larger than 1.68 in magnitude are reported in boldface. 
Table 6: Hedge Portfolio Returns

\begin{tabular}{c|ccc|ccccc}
\hline & $\begin{array}{c}\text { Average } \\
\text { Return } \\
\text { \% month) }\end{array}$ & $\begin{array}{c}\mathrm{NW} \\
\text { t-stat }\end{array}$ & $\begin{array}{c}\text { Sharpe } \\
\text { Ratio }\end{array}$ & FVIX & $\mathrm{R}_{\mathrm{m}}-\mathrm{R}_{\mathrm{f}}$ & SMB & HML & UMD \\
\hline $\mathbf{1 9 9 0 - 2 0 0 4}$ & & & & & & & & \\
FIVOIL & -0.13 & $(-0.55)$ & -0.04 & 0.32 & -0.05 & -0.03 & 0.05 & 0.22 \\
FVIX & -0.53 & $\mathbf{( - 2 . 0 1 )}$ & -0.15 & & -0.42 & 0.00 & 0.39 & 0.38 \\
$\mathrm{R}_{\mathrm{m}}-\mathrm{R}_{\mathrm{f}}$ & 0.67 & $\mathbf{( 2 . 0 2 )}$ & 0.16 & & & 0.16 & -0.53 & -0.25 \\
SMB & 0.10 & $(0.40)$ & 0.03 & & & & -0.42 & 0.10 \\
HML & 0.39 & $(1.17)$ & 0.12 & & & & & 0.05 \\
UMD & 1.01 & $\mathbf{( 3 . 5 5 )}$ & 0.21 & & & & & \\
$\mathbf{2 0 0 5 - 2 0 1 2}$ & & & & & & & & \\
FIVOIL & -0.50 & $\mathbf{( - 2 . 6 8 )}$ & -0.16 & 0.11 & -0.19 & 0.02 & 0.07 & 0.02 \\
FVIX & -0.32 & $(-0.95)$ & -0.08 & & -0.58 & -0.33 & -0.35 & 0.54 \\
$R_{\mathrm{m}}-\mathrm{R}_{\mathrm{f}}$ & 0.43 & $(0.73)$ & 0.09 & & & 0.44 & 0.35 & -0.41 \\
SMB & 0.14 & $(0.78)$ & 0.06 & & & & 0.22 & -0.13 \\
HML & 0.10 & $(0.42)$ & 0.04 & & & & & -0.33 \\
UMD & -0.01 & $(-0.01)$ & -0.00 & & & & & \\
\hline
\end{tabular}

Notes: This table reports average monthly returns on the hedge portfolios FIVOil (FVIX), which are constructed from sensitivities to the factor $\Delta$ IVOil $(\Delta \mathrm{VIX})$. We form hedge portfolios by going long stocks in the quintile with the highest sensitivity to $\Delta$ IVOil $(\Delta$ VIX) and shorting stocks in the quintile with the lowest sensitivity to $\Delta$ IVOil $(\Delta V I X)$. We also report the correlation of FIVOil with FVIX, $\mathrm{R}_{\mathrm{m}}-\mathrm{R}_{\mathrm{f}}$, SMB, HML, and UMD. The Newey-West t-statistics with 12 lags are reported in parentheses. T-stats larger than 1.68 in magnitude are reported in boldface. FVIX is constructed similarly to FIVOil, except using the regression: $R_{i, t}-R_{f, t}=\beta_{0}^{i}+\beta_{M K T}^{i}\left(R_{m, t}-R_{f, t}\right)+\beta_{V I X}^{i} \Delta V I X_{t}+\varepsilon_{i, t}$. 
Table 7: The Price of Oil Volatility Risk

\section{Using Beta from the Full Sample of Monthly Returns}

\begin{tabular}{c|cccccccc}
\hline & & & & & & & & Ave. Adj. \\
& Constant & $\mathrm{R}_{\mathrm{m}}-\mathrm{R}_{\mathrm{f}}$ & FIVOil & FVIX & SMB & HML & UMD & $\mathrm{R}^{2}(\%)$ \\
\hline 1990-2004 & & & & & & & & \\
25 Mkt and IVOil Portfolio & 0.84 & -0.08 & -0.12 & & & & & 28.67 \\
& $(\mathbf{2 . 2 1})$ & $(-0.14)$ & $(-0.49)$ & & & & & \\
& 0.30 & 0.38 & -0.14 & & 0.32 & 0.41 & 0.04 & 44.55 \\
& $(0.75)$ & $(0.90)$ & $(-0.56)$ & & $(0.69)$ & $(0.69)$ & $(0.05)$ & \\
& 1.21 & -0.44 & & -0.61 & & & & 30.43 \\
& $\mathbf{4 . 3 5}$ & $(-1.07)$ & & $\mathbf{( - 2 . 3 7 )}$ & & & & \\
& 0.91 & -0.23 & & -0.56 & 0.08 & 0.33 & -0.56 & 45.65 \\
& $(\mathbf{2 . 6 0 )}$ & $(-0.58)$ & & $\mathbf{( - 2 . 2 5 )}$ & $(0.19)$ & $(0.71)$ & $(-0.78)$ & \\
\hline \multirow{5}{*}{$\mathbf{2 0 0 5 - 2 0 1 2}$ Mkt and VIX Portfolio } & & & & & & & & \\
& 0.32 & 0.15 & -0.58 & & & & & 35.67 \\
& $(0.70)$ & $(0.28)$ & $\mathbf{( - 2 . 6 9 )}$ & & & & & \\
& 0.40 & 0.12 & -0.60 & & -0.16 & 0.39 & 0.27 & 43.56 \\
& $(0.98)$ & $(0.22)$ & $\mathbf{( - 2 . 8 0 )}$ & & $(-0.59)$ & $(0.77)$ & $(0.25)$ & \\
& 0.38 & 0.07 & & -0.35 & & & & 34.45 \\
& $(1.04)$ & $(0.11)$ & & $(-0.96)$ & & & & \\
& 0.16 & 0.27 & & -0.35 & -0.03 & -0.22 & -0.35 & 45.60 \\
& $(0.46)$ & $(0.48)$ & & $(-0.98)$ & $(-0.06)$ & $(-0.78)$ & $(-0.36)$ & \\
\hline
\end{tabular}

Notes: This table reports the estimated price of risk when we use $\mathrm{R}_{\mathrm{m}}-\mathrm{R}_{\mathrm{f}}$, FIVOil (or FVIX), SMB, HML, and UMD as factors and the 25 portfolios sorted on $\beta_{M K T}$ and $\beta_{I V O i l}$ (or the 25 portfolios sorted on $\beta_{M K T}$ and $\left.\beta_{V I X}\right)$. For each factor model, we estimate the price of risks, $\lambda \mathrm{s}$, using the two-step procedure of FamaMacBeth (1973). In the first step we estimate $\beta$ s in time series regressions on the full-sample monthly returns of the 25 portfolios. In the second step, we estimate $\lambda$ s by running cross-sectional regressions on the $\beta \mathrm{s}$. We report the average of the cross-sectional regression coefficients and adjusted $\mathrm{R}^{2}$ in the cross-sectional regressions. The Newey-West t-statistics with 12 lags are reported in parentheses. T-stats larger than 1.68 in magnitude are reported in boldface. 
Table 8: The Price of Oil Volatility Risk

Using Rolling Betas from Daily Returns

\begin{tabular}{|c|c|c|c|c|c|c|c|c|}
\hline & Constant & $\mathrm{R}_{\mathrm{m}}-\mathrm{R}_{\mathrm{f}}$ & FIVOil & FVIX & SMB & HML & UMD & $\begin{array}{l}\text { Ave. Adj. } \\
\mathrm{R}^{2}(\%)\end{array}$ \\
\hline \multirow{5}{*}{$\begin{array}{l}\mathbf{1 9 9 0 - 2 0 0 4} \\
25 \mathrm{Mkt} \text { and IVOil Portfolio }\end{array}$} & & & & & & & & \\
\hline & 0.84 & 0.06 & -0.06 & & & & & 31.43 \\
\hline & $(2.27)$ & $(0.12)$ & $(-0.32)$ & & & & & \\
\hline & 0.82 & 0.05 & -0.06 & & 0.18 & 0.01 & 0.14 & 46.25 \\
\hline & $(3.02)$ & $(0.13)$ & $(-0.30)$ & & $(0.64)$ & $(0.03)$ & $(0.61)$ & \\
\hline \multirow[t]{4}{*}{$25 \mathrm{Mkt}$ and VIX Portfolio } & 0.93 & -0.04 & & -0.30 & & & & 30.77 \\
\hline & (3.14) & $(-0.11)$ & & $(-1.01)$ & & & & \\
\hline & 1.10 & -0.24 & & -0.34 & 0.17 & -0.01 & -0.06 & 46.17 \\
\hline & $(4.77)$ & $(-0.65)$ & & $(-1.21)$ & $(0.79)$ & $(-0.02)$ & $(-0.23)$ & \\
\hline \multicolumn{9}{|l|}{ 2005-2012 } \\
\hline \multirow[t]{4}{*}{$25 \mathrm{Mkt}$ and IVOil Portfolio } & 0.70 & -0.04 & -0.61 & & & & & 43.29 \\
\hline & $(1.63)$ & $(-0.10)$ & $(-2.53)$ & & & & & \\
\hline & 0.88 & -0.20 & -0.56 & & 0.56 & 0.48 & -0.12 & 54.09 \\
\hline & $(2.35)$ & $(-0.59)$ & $(-2.37)$ & & $(2.04)$ & (2.90) & $(-0.22)$ & \\
\hline \multirow[t]{4}{*}{$25 \mathrm{Mkt}$ and VIX Portfolio } & 0.54 & 0.08 & & -0.45 & & & & 38.40 \\
\hline & $(1.48)$ & $(0.16)$ & & $(-1.30)$ & & & & \\
\hline & 0.61 & 0.01 & & -0.52 & 0.45 & 0.27 & -0.33 & 50.97 \\
\hline & $(\mathbf{1 . 8 5})$ & $(0.03)$ & & $(-1.50)$ & $(\mathbf{1 . 6 9 )}$ & $(1.31)$ & $(-0.47)$ & \\
\hline
\end{tabular}

Notes: This table reports the estimated price of risk when we use $\mathrm{R}_{\mathrm{m}}-\mathrm{R}_{\mathrm{f}}$, FIVOil (or FVIX), SMB, HML, and UMD as factors and the 25 portfolios sorted on $\beta_{M K T}$ and $\beta_{I V O i l}$ (or the 25 portfolios sorted on $\beta_{M K T}$ and $\beta_{V I X}$ ). We estimate the prices of risk, $\lambda \mathrm{s}$, using the two-step procedure of Fama-MacBeth (1973). In the first step, we estimate the $\beta$ s in time series regressions on daily returns using a rolling 1-month sample. We then estimate $\lambda$ s by running cross-sectional regressions on monthly returns for each month. We report the average regression coefficients and adjusted $\mathrm{R}^{2}$ in the cross-sectional regressions. The Newey-West t-statistics with 12 lags are reported in parentheses. T-stats larger than 1.68 in magnitude are reported in boldface. 
Table 9: The Price of Volatility Risk

Using 49 Industry Portfolios

\begin{tabular}{|c|c|c|c|c|c|c|c|c|}
\hline & Constant & $\mathrm{R}_{\mathrm{m}}-\mathrm{R}_{\mathrm{f}}$ & FIVOIL & FVIX & SMB & HML & UMD & $\begin{array}{l}\text { Ave. } \\
\text { Adj. } \mathrm{R}^{2} \\
(\%)\end{array}$ \\
\hline \multirow[t]{6}{*}{ 1990-2004 } & & & & & & & & \\
\hline & $\begin{array}{c}0.42 \\
(1.20)\end{array}$ & $\begin{array}{c}0.31 \\
(0.82)\end{array}$ & $\begin{array}{c}-0.08 \\
(-0.51)\end{array}$ & & & & & 13.66 \\
\hline & $\begin{array}{c}0.36 \\
(1.06)\end{array}$ & $\begin{array}{c}0.45 \\
(1.22)\end{array}$ & $\begin{array}{c}-0.04 \\
(-0.24)\end{array}$ & & $\begin{array}{c}-0.39 \\
\mathbf{( - 2 . 1 6 )}\end{array}$ & $\begin{array}{c}0.03 \\
(0.17)\end{array}$ & $\begin{array}{c}0.29 \\
(1.53)\end{array}$ & 23.67 \\
\hline & $\begin{array}{c}0.46 \\
(134)\end{array}$ & $\begin{array}{c}0.29 \\
(078)\end{array}$ & & $\begin{array}{l}-0.10 \\
-031)\end{array}$ & & & & 13.55 \\
\hline & 0.43 & 0.36 & & -0.25 & -0.37 & 0.09 & 0.31 & 22.78 \\
\hline & (1.23) & $(0.92)$ & & $(-0.84)$ & $(-1.89)$ & $(0.44)$ & (1.81) & \\
\hline \multirow[t]{8}{*}{ 2005-2012 } & & & & & & & & \\
\hline & $\begin{array}{c}0.28 \\
(0.45)\end{array}$ & $\begin{array}{c}0.35 \\
(0.68)\end{array}$ & $\begin{array}{c}-0.56 \\
\mathbf{( - 2 . 6 7 )}\end{array}$ & & & & & 23.05 \\
\hline & 0.24 & 0.34 & -0.43 & & 0.09 & 0.17 & -0.01 & 31.84 \\
\hline & $(0.40)$ & $(0.82)$ & $(-1.88)$ & & $(0.54)$ & $(0.93)$ & $(-0.03)$ & \\
\hline & 0.37 & 0.29 & & -0.50 & & & & 21.53 \\
\hline & $(0.61)$ & $(0.62)$ & & $(-1.35)$ & & & & \\
\hline & 0.34 & 0.26 & & -0.50 & 0.10 & 0.18 & 0.03 & 32.12 \\
\hline & $(0.61)$ & $(0.63)$ & & $(-1.53)$ & $(0.59)$ & $(0.91)$ & $(0.08)$ & \\
\hline
\end{tabular}

Notes: We report the estimated prices of risk, $\lambda \mathrm{s}$, using 49 Fama-French industry portfolios and the twostep procedure of Fama-MacBeth (1973). In the first step, we estimate the $\beta$ s in time series regressions on daily returns using a rolling 1-month sample. We then estimate $\lambda$ s by running cross-sectional regressions on monthly returns for each month. We report the average regression coefficients and adjusted $\mathrm{R}^{2}$ in the cross-sectional regressions. The Newey-West t-statistics with 12 lags are reported in parentheses. T-stats larger than 1.68 in magnitude are reported in boldface. 
Table 10: Sorting on Orthogonalized AIVOil Loadings

\begin{tabular}{c|cccccc}
\hline & \multicolumn{7}{|c}{$\Delta$ IVOil Orthogonalized by $\Delta$ VIX } \\
& 1 & 2 & 3 & 4 & 5 & $5-1$ \\
\hline $\begin{array}{c}\text { 1990-2004 } \\
\text { Beta }\end{array}$ & -0.72 & -0.24 & -0.01 & 0.22 & 0.69 & 1.41 \\
Average Return (\%) & 1.07 & 1.11 & 1.08 & 1.15 & 1.07 & 0.00 \\
& & & & & & $-0.01)$ \\
Carhart Alpha (\%) & 0.20 & 0.16 & 0.07 & 0.07 & -0.06 & -0.26 \\
& & & & & & $(-0.78)$ \\
\hline 2005-2012 & & & & & & \\
Beta & -0.61 & -0.20 & -0.01 & 0.18 & 0.57 & 1.17 \\
Average Return (\%) & 1.06 & 0.81 & 0.67 & 0.53 & 0.40 & -0.66 \\
Carhart Alpha (\%) & 0.47 & 0.25 & 0.13 & -0.04 & -0.26 & -0.73 \\
& & & & & & $\mathbf{( - 1 . 8 8 )}$ \\
\hline
\end{tabular}

Notes: At the end of each month, we run the following regression on daily returns during the month:

$$
R_{i, t}-R_{f, t}=\beta_{0}^{i}+\beta_{M K T}^{i}\left(R_{m, t}-R_{f, t}\right)+\beta_{I V O i l}^{i} e_{t}^{I V O i l}+\varepsilon_{i, t},
$$

where $e_{t}^{I V O i l}$ is the residual from a regression of $\triangle I$ VOil on $\triangle$ VIX in each month. We then sort stocks into quintiles based on $\beta_{\text {IVoil }}$ with the first quintile having the lowest beta and the fifth having the highest beta. We form five value-weighted portfolios at the end of each month and record the return of each quintile portfolio during the following month. We repeat the procedure by rolling the beta estimation window forward one month at a time. The table reports the average pre-ranking beta and post-ranking monthly returns for each quintile portfolio, as well as post-ranking Jensen's alpha based on the Carhart four-factor model. We report the monthly alpha computed as the daily alpha multiplied by 21 . Newey-West $\mathrm{t}$ statistics with 12 lags for monthly returns and 21 lags for daily alphas are reported in parentheses. T-stats larger than 1.68 in magnitude are reported in boldface. 
Table 11: Sorting on $\Delta I V O i l$ or $\Delta$ VIX Loadings

\begin{tabular}{|c|c|c|c|c|c|c|c|c|c|c|c|c|}
\hline & \multicolumn{6}{|c|}{$\begin{array}{c}\text { Sort on } \Delta \text { IVOil } \\
\text { Quintile Portfolios }\end{array}$} & \multicolumn{6}{|c|}{$\begin{array}{c}\text { Sort on } \Delta \text { VIX } \\
\text { Quintile Portfolios }\end{array}$} \\
\hline & 1 & 2 & 3 & 4 & 5 & $5-1$ & 1 & 2 & 3 & 4 & 5 & $5-1$ \\
\hline $1990-2004$ & & & & & & & & & & & & \\
\hline Beta & -0.73 & -0.24 & -0.01 & 0.23 & 0.70 & 1.43 & -1.45 & -0.49 & -0.01 & 0.46 & 1.46 & 2.91 \\
\hline Average Return (\%) & 1.05 & 1.08 & 1.06 & 1.19 & 1.10 & $\begin{array}{c}0.05 \\
(0.19)\end{array}$ & 1.26 & 1.19 & 1.18 & 0.97 & 0.74 & $\begin{array}{c}-0.52 \\
(-2.21)\end{array}$ \\
\hline Carhart Alpha (\%) & 0.16 & 0.11 & 0.01 & 0.15 & 0.02 & $\begin{array}{c}-0.15 \\
(-0.43) \\
\end{array}$ & 0.37 & 0.22 & 0.16 & -0.11 & -0.36 & $\begin{array}{c}-0.73 \\
\mathbf{( - 2 . 0 6 )} \\
\end{array}$ \\
\hline 2005-2012 & & & & & & & & & & & & \\
\hline Beta & -0.62 & -0.21 & -0.01 & 0.19 & 0.58 & 1.20 & -1.03 & -0.33 & 0.02 & 0.39 & 1.15 & 2.19 \\
\hline Average Return (\%) & 1.02 & 0.80 & 0.66 & 0.51 & 0.48 & $\begin{array}{c}-0.54 \\
(-\mathbf{1 . 9 9})\end{array}$ & 0.82 & 0.54 & 0.58 & 0.58 & 0.64 & $\begin{array}{l}-0.19 \\
(-0.56)\end{array}$ \\
\hline Carhart Alpha (\%) & 0.43 & 0.25 & 0.12 & -0.06 & -0.18 & $\begin{array}{c}-0.61 \\
(-1.59) \\
\end{array}$ & 0.24 & -0.02 & 0.04 & -0.02 & -0.03 & $\begin{array}{r}-0.27 \\
(-0.69) \\
\end{array}$ \\
\hline
\end{tabular}

Notes: At the end of each month, we run the following regression on daily returns during the month:

$$
R_{i, t}-R_{f, t}=\beta_{0}^{i}+\beta_{M K T}^{i}\left(R_{m, t}-R_{f, t}\right)+\beta_{I V O i l}^{i} \Delta I V O i l_{t}+\beta_{V I X}^{i} \Delta V I X_{t}+\varepsilon_{i, t} .
$$

We then sort the stocks into quintiles based on $\beta_{I V O i l}$ or $\beta_{V I X}$ with the first quintile having the lowest beta and the fifth having the highest beta. We form five value-weighted portfolios at the end of each month and record the return of each quintile portfolio during the following month. We repeat the procedure by rolling the beta estimation window forward one month at a time. The table reports the average pre-ranking beta and post-ranking monthly returns for each quintile portfolio, as well as post-ranking Jensen's alpha based on the Carhart four-factor model. We report the monthly alpha computed as the daily alpha multiplied by 21 . Newey-West t-statistics with 12 lags for monthly returns and 21 lags for daily alphas are reported in parentheses. T-stats larger than 1.68 in magnitude are reported in boldface. 
Table 12: Sorting on $\Delta R V$ Loadings

\begin{tabular}{c|cccccc}
\hline & \multicolumn{7}{|c}{ Sort on $\Delta \mathrm{E}_{\mathrm{t}}[\mathrm{RV}]$} \\
& 1 & 2 & 3 & 4 & 5 & $5-1$ \\
\hline $\begin{array}{c}\text { 1990-2004 } \\
\text { Beta }\end{array}$ & -1.25 & -0.41 & -0.01 & 0.39 & 1.22 & 2.47 \\
Average Return (\%) & 0.99 & 1.03 & 1.06 & 1.23 & 1.15 & 0.16 \\
& & & & & & $(0.56)$ \\
Carhart Alpha (\%) & -0.03 & -0.02 & 0.01 & 0.21 & 0.26 & 0.28 \\
& & & & & & $(1.00)$ \\
\hline $\begin{array}{c}\text { 2005-2012 } \\
\text { Beta }\end{array}$ & -0.74 & -0.25 & -0.01 & 0.22 & 0.70 & 1.45 \\
Average Return (\%) & 0.62 & 0.70 & 0.65 & 0.69 & 0.48 & -0.13 \\
& & & & & & $(-0.39)$ \\
Carhart Alpha (\%) & -0.04 & 0.13 & 0.11 & 0.15 & -0.14 & -0.10 \\
& & & & & & $(-0.27)$ \\
\hline
\end{tabular}

Notes: We compute realized volatility calculated from high frequency oil futures data. We use the heterogeneous autoregressive (HAR) model to forecast expected RV. We set the forecast period to 21 business days to match the horizon of IVOil. At the end of each month, we run the following regressions on daily returns during the month:

$$
R_{i, t}-R_{f, t}=\beta_{0}^{i}+\beta_{M K T}^{i}\left(R_{m, t}-R_{f, t}\right)+\beta_{R V}^{i} \Delta E_{t}[\mathrm{RV}]+\varepsilon_{i, t} .
$$

We then sort stocks into quintiles based on $\beta_{R V}$, with the first quintile having the lowest beta and the fifth having the highest beta. We form five value-weighted portfolios at the end of each month and record the return of each quintile portfolio during the following month. We repeat the procedure by rolling the beta estimation window forward one month at a time. This table reports the average pre-ranking beta and postranking monthly returns for each quintile portfolio, and Jensen's alpha based on the Carhart four-factor model. We report monthly alpha which is daily alpha multiplied by 21 . Newey-West t-statistics with 12 lags for monthly returns and 21 lags for daily alphas are in parentheses. 
Table 13: Sorting on $\triangle$ VRP Loadings

\begin{tabular}{c|cccccc}
\hline & \multicolumn{7}{|c}{ Sort on $\Delta$ VRP } \\
& 1 & 2 & 3 & 4 & 5 & $5-1$ \\
\hline $\begin{array}{c}\text { 1990-2004 } \\
\text { Beta }\end{array}$ & -0.63 & -0.21 & -0.00 & 0.20 & 0.62 & 1.25 \\
Average Return (\%) & 1.13 & 1.20 & 1.14 & 1.00 & 1.07 & -0.06 \\
& & & & & & $(-0.18)$ \\
Carhart Alpha (\%) & 0.26 & 0.24 & 0.10 & -0.02 & -0.04 & -0.29 \\
& & & & & & $(-0.82)$ \\
\hline $\begin{array}{c}\text { 2005-2012 } \\
\text { Beta }\end{array}$ & -0.46 & -0.15 & -0.00 & 0.15 & 0.45 & 0.91 \\
Average Return (\%) & 0.85 & 0.81 & 0.54 & 0.64 & 0.32 & -0.52 \\
Carhart Alpha (\%) & 0.24 & 0.27 & 0.00 & 0.07 & -0.35 & -0.59 \\
& & & & & & $(-1.64)$ \\
\hline
\end{tabular}

Notes: We define the oil volatility risk premium as $V R P_{t}=I V O i l_{t}-E_{t}[R V]$. We use the heterogeneous autoregressive (HAR) model to forecast expected RV. At the end of each month, we run the following regressions on daily returns during the month:

$$
R_{i, t}-R_{f, t}=\beta_{0}^{i}+\beta_{M K T}^{i}\left(R_{m, t}-R_{f, t}\right)+\beta_{V R P}^{i} \Delta V R P_{t}+\varepsilon_{i, t} .
$$

We then sort stocks into quintiles based on $\beta_{V R P}$, with the first quintile having the lowest beta and the fifth having the highest beta. We form five value-weighted portfolios at the end of each month and record the return of each quintile portfolio during the following month. We repeat the procedure by rolling the beta estimation window forward one month at a time. The table reports the average pre-ranking beta and post-ranking monthly returns for each quintile portfolio, and Jensen's alpha based on the Carhart fourfactor model. We report monthly alphas which are daily alphas multiplied by 21 . Newey-West t-statistics with 12 lags for monthly returns and 21 lags for daily alphas are reported in parentheses. T-stats larger than 1.68 in magnitude are reported in boldface. 
Table 14: Sorting on Oil Return Loadings

\begin{tabular}{c|cccccc}
\hline & \multicolumn{7}{|c}{ Quintile Portfolios } \\
& 1 & 2 & 3 & 4 & 5 & $5-1$ \\
\hline $\begin{array}{c}\text { 1990-2004 } \\
\text { Beta }\end{array}$ & -0.49 & -0.16 & 0.00 & 0.17 & 0.51 & 1.00 \\
Average Return (\%) & 1.21 & 1.21 & 0.83 & 1.12 & 0.92 & -0.29 \\
& & & & & & $(-1.02)$ \\
Carhart Alpha (\%) & 0.33 & 0.24 & -0.16 & 0.12 & -0.13 & -0.46 \\
& & & & & & $(-1.41)$ \\
\hline $\begin{array}{c}\mathbf{2 0 0 5 - 2 0 1 2} \\
\text { Beta }\end{array}$ & -0.38 & -0.13 & 0.00 & 0.14 & 0.46 & 0.84 \\
Average Return (\%) & 0.58 & 0.72 & 0.64 & 0.59 & 0.90 & 0.33 \\
& & & & & & $(0.70)$ \\
Carhart Alpha (\%) & -0.06 & 0.16 & 0.07 & -0.02 & 0.27 & 0.32 \\
& & & & & & $(0.76)$ \\
\hline
\end{tabular}

Notes: We calculate oil returns from the closest-to-maturity futures prices. At the end of each month, we run the following regression on daily stock returns during the month

$$
R_{i, t}-R_{f, t}=\beta_{0}^{i}+\beta_{M K T}^{i}\left(R_{m, t}-R_{f, t}\right)+\beta_{\text {oil Ret }}^{i} \text { Oil Ret }_{t}+\varepsilon_{i, t} .
$$

We then sort stocks into quintiles based on $\beta_{\text {oil Ret }}$ with the first quintile having the lowest beta and the fifth having the highest beta. We form five value-weighted portfolios at the end of each month and record the returns of each quintile portfolio during the following month. We repeat the procedure by rolling the beta estimation window forward one month at a time. The table reports the average pre-ranking beta and post-ranking monthly returns for each quintile portfolio. We also report Jensen's alpha based on the Carhart four-factor model. We compute monthly alphas as daily alphas multiplied by 21 . Newey-West $\mathrm{t}-$ statistics with 12 lags for monthly returns and 21 lags for daily alphas are reported in parentheses. 
2014-46: Alessandro Giovannelli and Tommaso Proietti: On the Selection of Common Factors for Macroeconomic Forecasting

2014-47: $\quad$ Martin M. Andreasen and Andrew Meldrum: Dynamic term structure models: The best way to enforce the zero lower bound

2014-48: $\quad$ Tim Bollerslev, Sophia Zhengzi Li and Viktor Todorov: Roughing up Beta: Continuous vs. Discontinuous Betas, and the Cross-Section of Expected Stock Returns

2914-49: $\quad$ Tim Bollerslev, Viktor Todorov and Lai Xu: Tail Risk Premia and Return Predictability

2014-50: Kerstin Gärtner and Mark Podolskij: On non-standard limits of Brownian semistationary

2014-51: Mark Podolskij : Ambit fields: survey and new challenges

2014-52: Tobias Fissler and Mark Podolskij: Testing the maximal rank of the volatility process for continuous diffusions observed with noise

2014-53: Cristina M. Scherrer: Cross listing: price discovery dynamics and exchange rate effects

2014-54: Claudio Heinrich and Mark Podolskij: On spectral distribution of high dimensional covariation matrices

2014-55: $\quad$ Gustavo Fruet Dias and Fotis Papailias: Forecasting Long Memory Series Subject to Structural Change: A Two-Stage Approach

2014-56: Torben G. Andersen, Nicola Fusari and Viktor Todorov: The Risk Premia Embedded in Index Options

2014-57: Eduardo Rossi and Paolo Santucci de Magistris: Indirect inference with time series observed with error

2014-58: $\quad$ Anders Bredahl Kock and Haihan Tang: Inference in High-dimensional Dynamic Panel Data Models

2015-01 Tom Engsted, Simon J. Hviid and Thomas Q. Pedersen: Explosive bubbles in house prices? Evidence from the OECD countries

2015-02: Tim Bollerslev, Andrew J. Patton and Wenjing Wang: Daily House Price Indices: Construction, Modeling, and Longer-Run Predictions

2015-03: Christian M. Hafner, Sebastien Laurent and Francesco Violante: Weak diffusion limits of dynamic conditional correlation models

2015-04: Maria Eugenia Sanin, Maria Mansanet-Bataller and Francesco Violante: Understanding volatility dynamics in the EU-ETS market

2015-05: $\quad$ Peter Christoffersen and Xuhui (Nick) Pan: Equity Portfolio Management Using Option Price Information

2015-06: Peter Christoffersen and Xuhui (Nick) Pan: Oil Volatility Risk and Expected Stock Returns 